\title{
Numerical analysis of the behavior of light concrete panels with variations of thickness and door opening position in resisting static monotonic loads
}

\author{
Annisa Fitria Agustina, Saloma*, Siti Aisyah Nurjannah, Arie Putra Usman, and Hanafiah \\ Civil Engineering Department, Faculty of Engineering, Sriwijaya University, Indonesia
}

Received: 15-November-2020; Revised: 26-December-2020; Accepted: 28-December-2020

(C)2020 Annisa Fitria Agustina et al. This is an open access article distributed under the Creative Commons Attribution (CC BY) License, which permits unrestricted use, distribution, and reproduction in any medium, provided the original work is properly cited.

\begin{abstract}
This study covered numerical analysis models of lightweight concrete panels with a variety of thicknesses and door opening positions. The objective of this study was to determine the influence of the dimension of lightweight concrete nonstructural panels with door openings in resisting static lateral loads. The lightweight concrete became generally used since its' effectiveness in reducing gravity loads. Therefore, the lateral deformation of buildings due to the earthquake became smaller. However, the behavior of the lightweight concrete panels as non-structural elements still needed to be explored, especially under influence of structural elements when an earthquake occurred. There were three variations of the door opening positions on the panels. The varied thicknesses were $40 \mathrm{~mm}, 50 \mathrm{~mm}$, and $60 \mathrm{~mm}$ with and without the addition of wire mesh reinforcement. The panels were subjected to increased static monotonic loads until the panels were collapsed. The analysis results were the relation curves of loads and deformations, and the shapes of deformation that occurred on each model. The analysis results of each panel showed different behaviors and values. In general, the variation of thickness resulted in the conclusion that the thickest panels were able to resist higher loads. The use of wire mesh affected significantly panel behavior. The panels with wire mesh became more rigid so that the resisted loads were higher, but the deformation became smaller, and vice versa while the panel without a wire mesh resisted lower loads but the deformation became larger.
\end{abstract}

\section{Keywords}

The lightweight concrete panel, Static monotonic load, Door opening, Thickness variation, Wire mesh.

\section{Introduction}

The wall was one of the examples of non-structural elements that could be modified both on the material and the shape. The material modifications could affect the weight of walls and buildings. A reduction of building weight would minimize damages caused by earthquake loads [1], especially on high-rise buildings. This also would minimize risks on life when damages on non-structural elements occurred [2]. Concrete walls began to be widely used due to the weight, ease, and efficiency of the process. The lightweight concrete had been used as materials of nonstructural and structural panels [3]. One of the lightweight concrete materials contained Expanded Polystyrene (EPS) [4]. However, the performance of the lightweight concrete panels is still needed to be examined. The objective of this study was to determine the influence of dimension and door openings of lightweight concrete nonstructural panels in resisting static lateral loads.

*Author for correspondence 201
The normal concrete weight is $2,400 \mathrm{~kg} / \mathrm{m} 3$, the lightweight concrete is less than $1,200 \mathrm{~kg} / \mathrm{m} 3$ [5], while the weight of the ordinary masonry wall is $1,700 \mathrm{~kg} / \mathrm{m} 3$. The manufacturing of light concrete walls becomes optional because the modified materials reduced weight significantly and do not result in excessive loads on buildings.

Referring to the research, the panels are generally made with the addition of opening doors in the middle and side positions [6]. Usually, the panels consisted of normal or high-quality concrete materials with reinforcement of wire mesh in longitudinal and transversal, as well as diagonal directions at the end of the openings. This study discussed the walls using lightweight concrete materials in the manufacture. The weight of the used light concrete was $950-1,100 \mathrm{~kg} / \mathrm{m} 3$ [7].

These walls were called lightweight concrete panels and modeled in three variations of the door opening positions. The opening positions were made from the 
center to the side of the panel. Each model was made of thickness variation also with and without the use of wire mesh. There was some numerical analysis to determine the panel behavior due to static monotonic loads.

This research generated the relation curves of loads and deformations that occurred in each panel model. The results were then compared based on variations of opening positions, thickness, also with and without the use of wire mesh.

\section{Methodology}

The panels were modeled with variations in door opening positions with a panel size of $1500 \mathrm{~mm} \times$ $1500 \mathrm{~mm}$, and the thickness variation of the panels of $40 \mathrm{~mm}, 50 \mathrm{~mm}$, and $60 \mathrm{~mm}$. The diameter of the wire mesh was $4 \mathrm{~mm}$ with a space of $150 \mathrm{~mm}$ both in $\mathrm{x}$ and $y$ directions. The dimension of panels was based on the common industrial products, as well as the diameter and space of the wire mesh. The wire mesh material properties were based on the previous research with a yield strength (f_y), ultimate strength $\left(f \_u\right)$, strain (E_y), and modulus of elasticity (E_s) consecutive were $424.50 \mathrm{MPa}, 538.70 \mathrm{MPa}, 0.0025$ and 177,570 MPa [8]. The concrete material data was taken based on the test of foamed concrete using EPS. The concrete compressive strength $\left(f \mathrm{f}^{\wedge^{\prime}}\right)$ at the age of 28 days used in this study was 5.224 MPa with a strain of 0.00235 [9]. A modeling illustration of each variation of the door opening position can be seen in Figure 1.

The analysis for obtaining deformation was based on the Newton-Rhapson method. Each node of every concrete and wire mesh element established a relation of deformations, forces, and stiffnesses, as described in equations (1) and (2).

$$
\begin{aligned}
& {\left[K_{x}\right]\left\{\Delta u_{x}\right\}=\left\{F^{e}\right\}-\left\{F_{x}^{n r}\right\}} \\
& \left\{u_{x+1}\right\}=\left\{u_{x}\right\}+\left\{\Delta u_{x}\right\}
\end{aligned}
$$

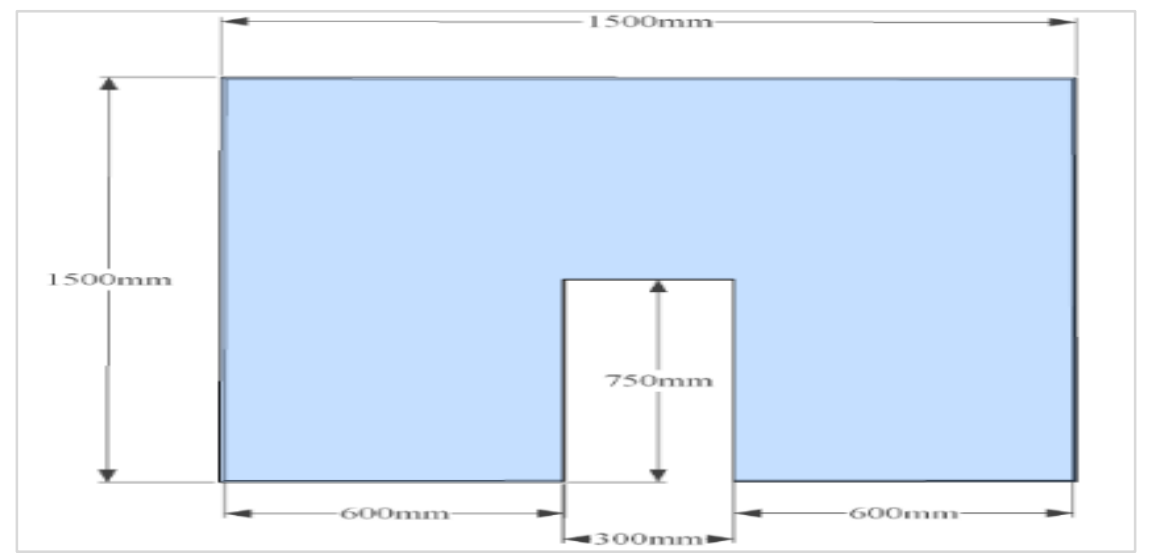

a. Type 1 panel

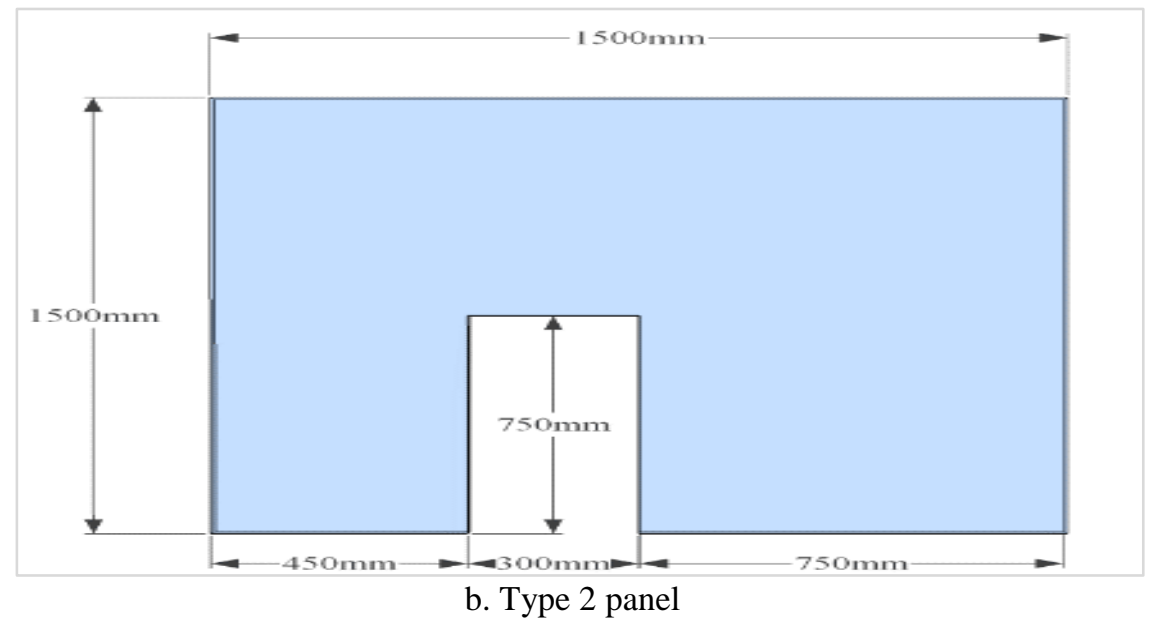




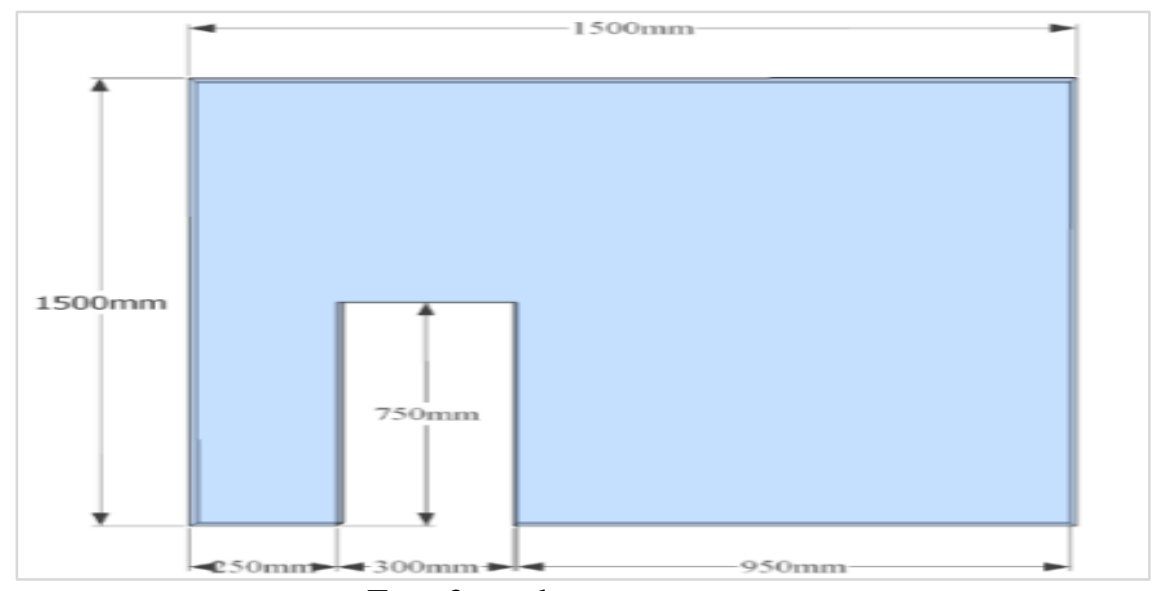

c. Type 3 panel

Figure 1 Panel models with a variation of door opening position

where $\left[K_{x}\right],\left\{u_{x}\right\}$, and $\left\{F_{x}^{n r}\right\}$ were stiffness matrix, deformation, and load vectors, respectively. The iteration using equation 2 resulted in deformation values [10]. The ultimate crack and crush conditions in concrete are modeled based on William and Warnke's theory [11].

The position of the door opening on the type 1 panel was in the center of the panel mass. The axis positions of the door opening on type 2 and 3 panels were 150 and $200 \mathrm{~mm}$ from the center of the panel mass, respectively, considering the available space of wire mesh [12]. The lateral loadings were subjected gradually to the panels in the form of static monotonic loads until the panels achieved ultimate condition. The lateral loads were located in the top position of the panels as seen in Figure 2 [13]. The loads were given gradually by an increment of $250 \mathrm{~N}$, which were divided into some nodes to represent an area that was subjected to the lateral loads. These areas covered the thickness of the panel and in square shapes.

The entered data in the input phase was the light concrete mechanical and wire mesh properties, as well as the panel dimensions, steel plate material, and lateral static monotonic load data. The steel plates were needed to prevent panels from buckling $[13,14]$. The size of the concrete mesh was $50 \mathrm{~mm}$ for each length and width, while the mesh size of thickness was $5 \mathrm{~mm}$. This meshing process had been conducted by creating specific nodes that represented each length, width, and thickness of the concrete panels.

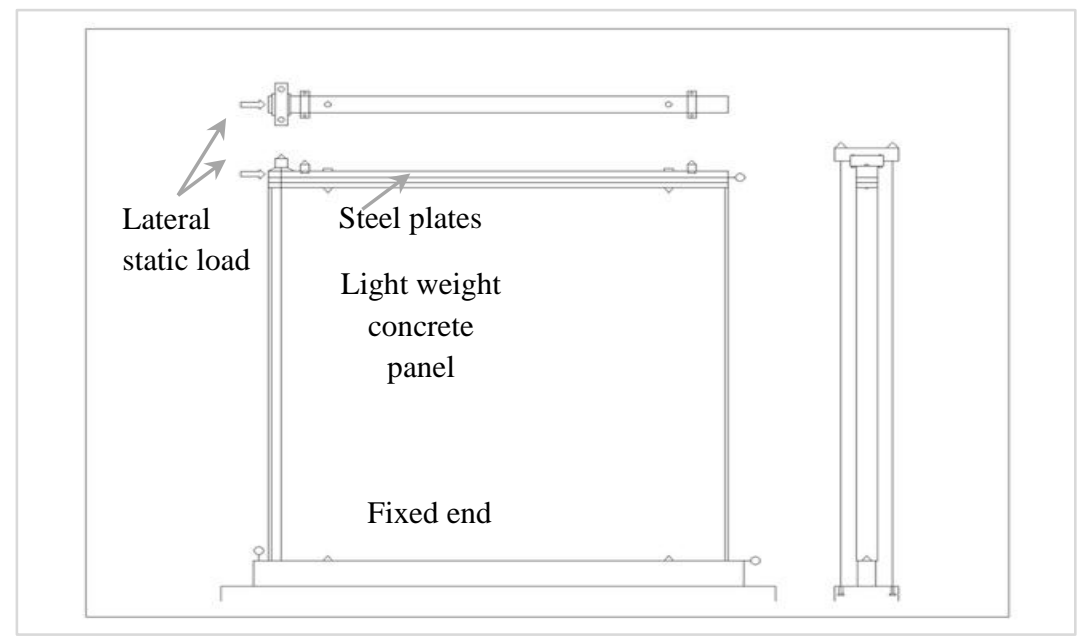

Figure 2 The static lateral load set up 


\section{Result and discussion}

3.1Load and deformation connection

3.1.1Load and deformation connection with thickness variation without wire mesh

The load and deformation connection curves of three type 1 panels with thickness variation without wire mesh are shown in Figure 3. The type 1 panel without wire mesh with a thickness of $40 \mathrm{~mm}$ collapsed at a load of $2.67 \mathrm{kN}$ with a $6.54 \mathrm{~mm}$ deformation. The type 1 panel without wire mesh with a thickness of $50 \mathrm{~mm}$ collapsed on the load of $3.58 \mathrm{kN}$ with deformation of $21.56 \mathrm{~mm}$. The type 1 panel without wire mesh with a thickness of $60 \mathrm{~mm}$ collapsed at a load of $3.92 \mathrm{kN}$ with an $18.14 \mathrm{~mm}$ deformation. The strength of type 1 panels without wire mesh with thicknesses of $50 \mathrm{~mm}$ and $60 \mathrm{~mm}$ under the static monotonic loads increased $34.08 \%$ and $46.82 \%$ compared to the one with $40 \mathrm{~mm}$ thickness, respectively.

Figure 4 presents load and deformation connection curves of type 2 panels with thickness variations without wire mesh. The type 2 panel with a thickness of $40 \mathrm{~mm}$ was able to resist the static monotonic load of $3.00 \mathrm{kN}$ with $22.16 \mathrm{~mm}$ deformation. The type 2 panel with a thickness of $50 \mathrm{~mm}$ and $60 \mathrm{~mm}$ achieved ultimate loads of 3.50 and $4.00 \mathrm{kN}$, with deformation of $28.09 \mathrm{~mm}$ and $25.68 \mathrm{~mm}$, respectively. The static monotonic loads increased significantly by $16.67 \%$ and $33.33 \%$ on type 2 panels with a thickness of 50 $\mathrm{mm}$ and $60 \mathrm{~mm}$, respectively, compared to the one with a thickness of $40 \mathrm{~mm}$. It showed that the type 2 panel with a thickness of $60 \mathrm{~mm}$ achieved the highest monotonic static load. It indicated that the thickness and dimension of the panels influenced the stiffness and achieved ultimate loads [15].

Figure 5 shows the load and deformation relation curves with thickness variations on the type 3 panel without wire mesh. The type 3 panel with a thickness of $40 \mathrm{~mm}$ was only able to restraint the static monotonic load of $2.83 \mathrm{kN}$ with a $30.27 \mathrm{~mm}$ deformation. The type 3 panels with thicknesses of $50 \mathrm{~mm}$ and $60 \mathrm{~mm}$ could resist the static monotonic loads of $4.58 \mathrm{kN}$ and $5.50 \mathrm{kN}$ with the deformations of 26.93 and $22.98 \mathrm{~mm}$, respectively. The panel thicknesses of 50 and $60 \mathrm{~mm}$ improved the load capability of $61.84 \%$ and $94.35 \%$, respectively, compared to the thickness of $40 \mathrm{~mm}$. From the results and analysis of the three types of a panel with thickness variation, it could be concluded that a panel with a $60 \mathrm{~mm}$ thickness could resist the highest lateral load compared to the panels with thicknesses of 40 and $50 \mathrm{~mm}$.

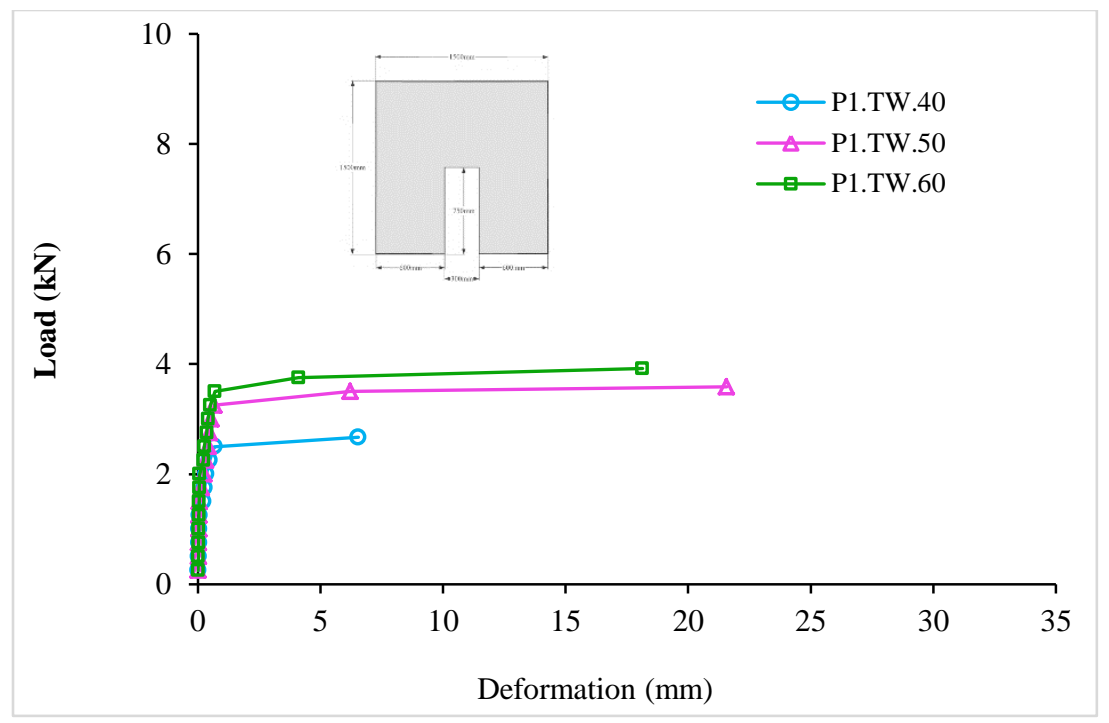

Figure 3 Load vs deformation curves of type 1 panel with thickness variation without wire mesh 


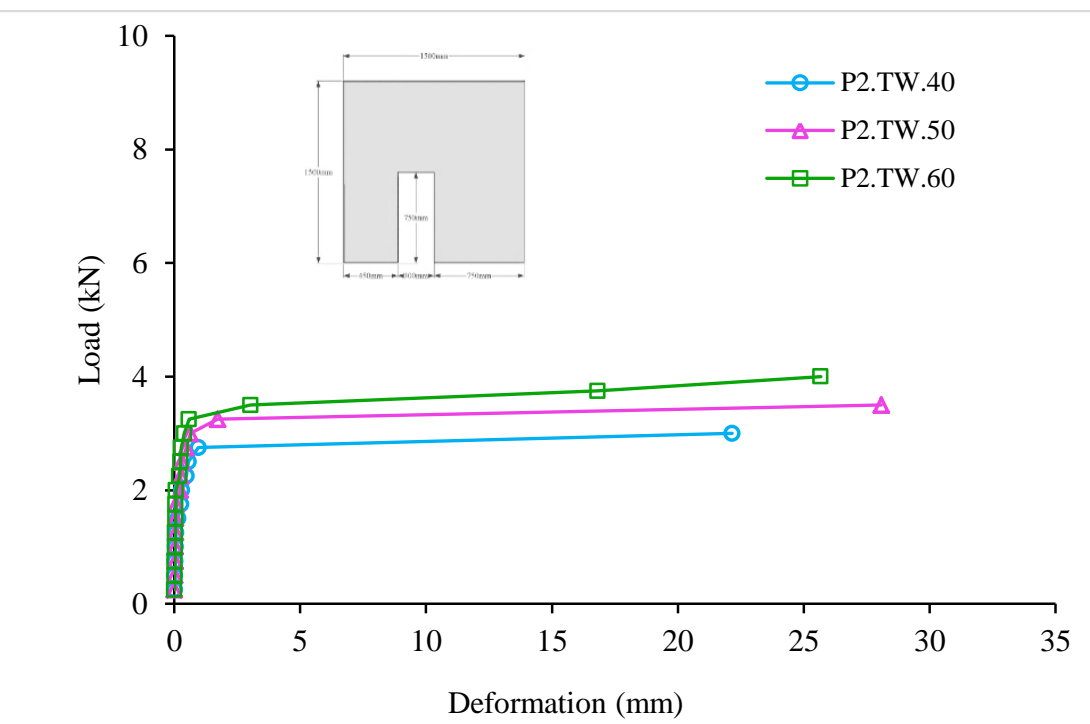

Figure 4 Load vs deformation curves of type 2 panel with thickness variation without wire mesh

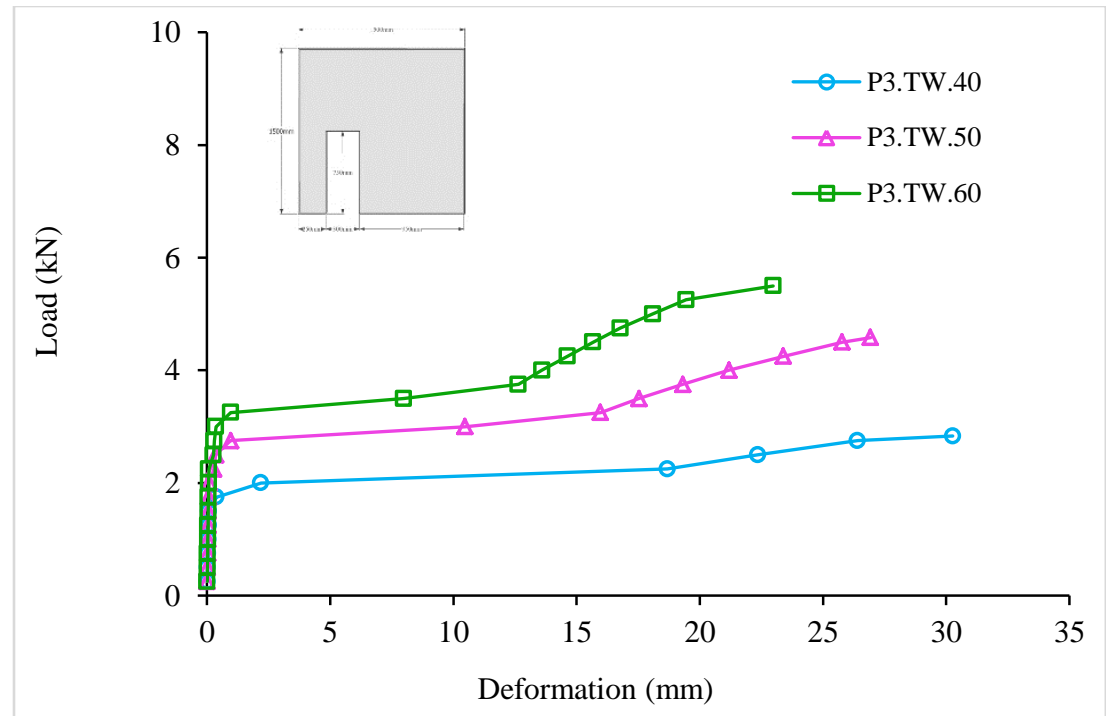

Figure 5 Load vs deformation curves of type 3 panel with thickness variation without wire mesh

3.1.2Load and deformation connection with variation in door opening position without wire mesh

Figures 6 to 8 show the load and deformation relation curves of the panels with variations of the door opening position without wire mesh. The panel thicknesses were compared equally, then it showed a certain panel that could resist the highest load. Figure 6 showed the load and deformation relation with the variation of the door opening position without wire mesh with a panel thickness of $40 \mathrm{~mm}$. The type 1 panel was capable to receive a load of $2.67 \mathrm{kN}$ with deformation of $6.54 \mathrm{~mm}$. The type 2 panel could resist loads up to $3.00 \mathrm{kN}$ with deformation of 22.16 $\mathrm{mm}$. The type 3 panel was only able to resist a load of $2.83 \mathrm{kN}$ with a deformation of $30.27 \mathrm{~mm}$. The type 3 panel suffered the largest deformation while the type 2 panel was able to resist the highest load. Figure 7 presents the load and deformation relation with a variation of the door opening position with a thickness of $50 \mathrm{~mm}$ without wire mesh. The type 1 panel collapsed at a load of $3.58 \mathrm{kN}$ with a $21.56 \mathrm{~mm}$ deformation. The type 2 panel collapsed at a load of $3.50 \mathrm{kN}$ with a deformation of $28.09 \mathrm{~mm}$. The type 3 panel collapsed at a load of $4.58 \mathrm{kN}$ with deformation of $26.93 \mathrm{~mm}$. The type 3 panel with a thickness of 50 
Annisa Fitria Agustina et al.

$\mathrm{mm}$ could resist the highest load, while the largest deformation occurred on the type 2 panel.

Figure 8 presents load and deformation relation curves with the variation position of door opening on the panel with a thickness of $60 \mathrm{~mm}$ without wire mesh. The type 1 panel suffered a collapse in the static monotonic load of $3.92 \mathrm{kN}$ with an $18.14 \mathrm{~mm}$ deformation. The type 2 panel collapsed at a load of $4.00 \mathrm{kN}$ with a $25.68 \mathrm{~mm}$ deformation. The type 3 panel collapsed at $5.50 \mathrm{kN}$ with a $22.98 \mathrm{~mm}$ deformation. The type 3 panel with a thickness of 60 $\mathrm{mm}$ could receive the highest load, while the largest deformation occurred on the type 2 panel.

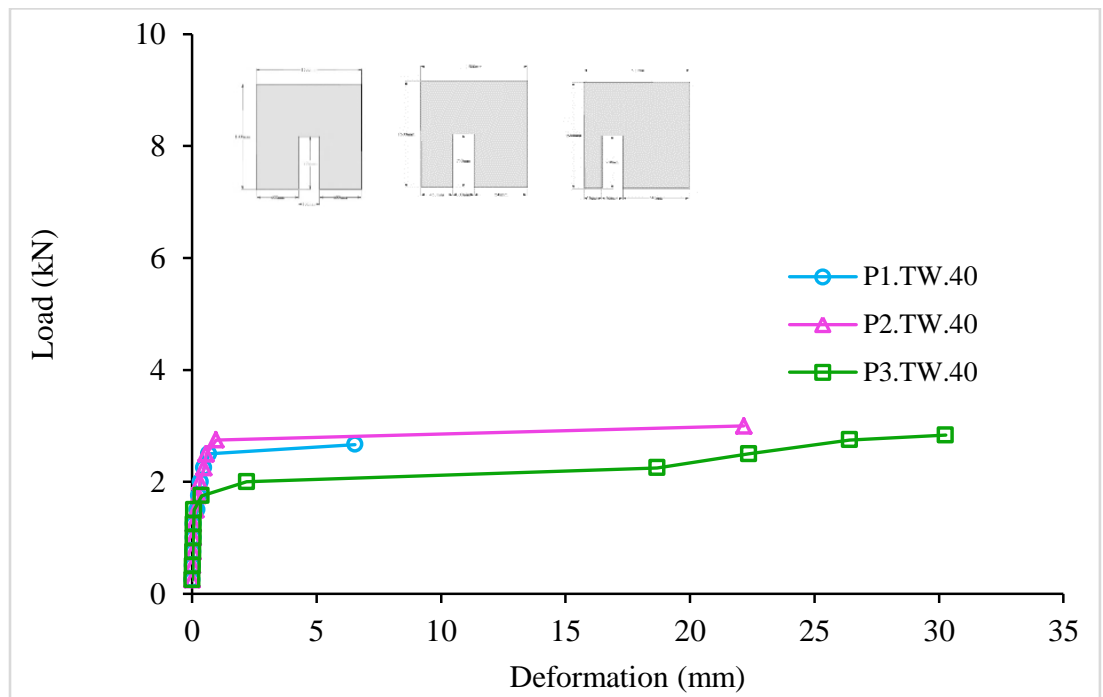

Figure 6 Load vs deformation curves with a variation of the door opening position without wire mesh with a thickness of $40 \mathrm{~mm}$

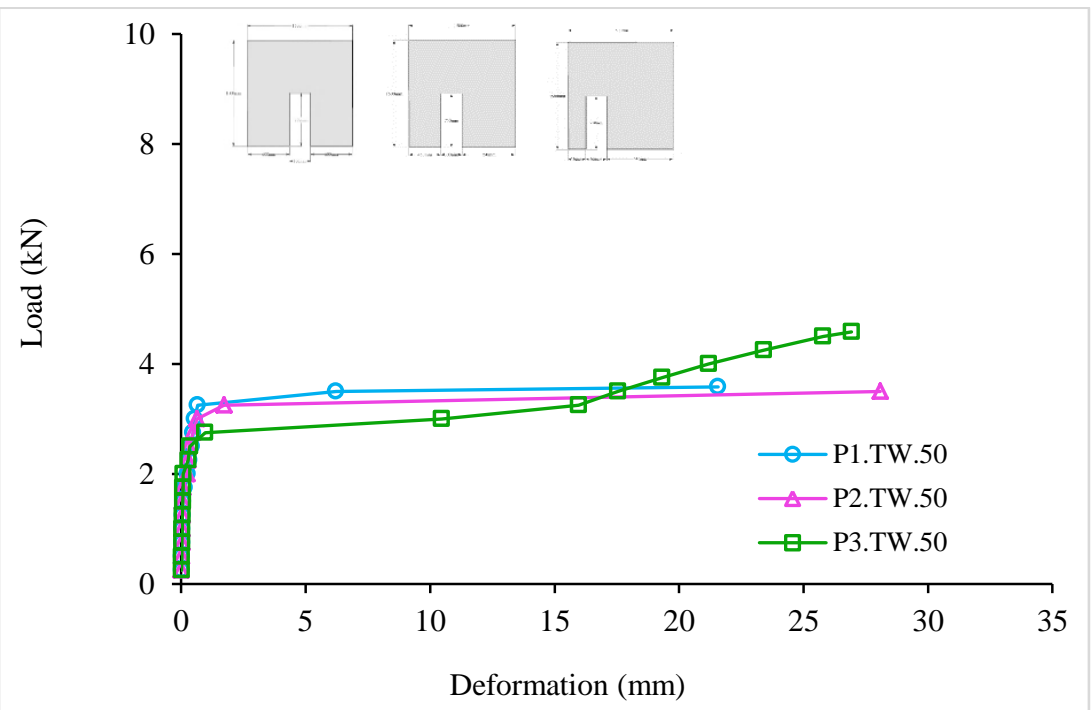

Figure 7 Load vs deformation curves with a variation of the door opening position without wire mesh with a thickness of $50 \mathrm{~mm}$ 


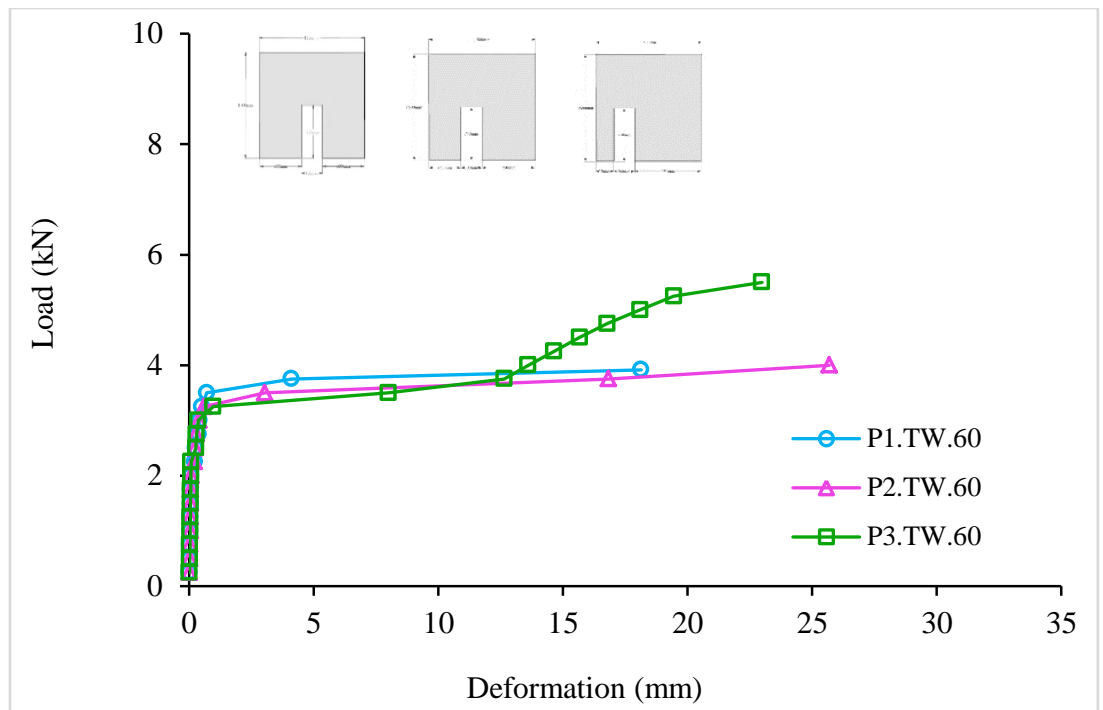

Figure 8 Load vs deformation curves with a variation of the door opening position without wire mesh with a thickness of $60 \mathrm{~mm}$

3.1.3Load and deformation connection of panel with wire mesh and thickness variation

Figure 9 presents load and deformation connection curves of type 1 panels with thickness variation and wire mesh. The panel with a thickness of $40 \mathrm{~mm}$ collapsed at a load of $14.08 \mathrm{kN}$ with a $5.82 \mathrm{~mm}$ deformation. The panel with a thickness of $50 \mathrm{~mm}$ collapsed at the load of $14.33 \mathrm{kN}$ with deformation of $5.22 \mathrm{~mm}$. The panel with a thickness of $60 \mathrm{~mm}$ collapsed at a load of $15.83 \mathrm{kN}$ with a $5.08 \mathrm{~mm}$ deformation. The thickness variation of type 1 panel with wire mesh influenced the resisted loads, where the panel with a thickness of $60 \mathrm{~mm}$ could resist the highest static monotonic load compared to panels with thicknesses of 40 and $50 \mathrm{~mm}$. The deformation decreased with the addition of the panel thickness. The load and deformation relation curves of type 2 panels with wire mesh and thickness variations can be seen in Figure 10. The type 2 panel with a thickness of $40 \mathrm{~mm}$ was only able to resist the static monotonic load of $13.08 \mathrm{kN}$ with a $6.43 \mathrm{~mm}$ deformation. The type 2 panel with a thickness of 50 $\mathrm{mm}$ could resist the load up to $15.83 \mathrm{kN}$ with a 6.09 $\mathrm{mm}$ deformation. The type 2 panel with a thickness of $60 \mathrm{~mm}$ could resist the load up to $17.5 \mathrm{kN}$ with deformation of $5.88 \mathrm{~mm}$. From all of the three variations of thickness of the type 2 panels, the one with a thickness of $60 \mathrm{~mm}$ could resist the highest load with a smaller deformation than the ones with thicknesses of 40 and $50 \mathrm{~mm}$, respectively.

Figure 11 shows the load and deformation curves with thickness variation on the type 3 panel with wire mesh. The type 3 panel with a thickness of $40 \mathrm{~mm}$ was only able to withstand the load up to $12.42 \mathrm{kN}$ with a $7.80 \mathrm{~mm}$ deformation. The type 3 panel with a thickness of $50 \mathrm{~mm}$ collapsed at $16.67 \mathrm{kN}$ load and deformation of $7.09 \mathrm{~mm}$. The type 3 panel with a thickness of $60 \mathrm{~mm}$ collapsed at a load of $18.00 \mathrm{kN}$ with deformation of $6.90 \mathrm{~mm}$. The type 3 panel with a thickness of $60 \mathrm{~mm}$ could receive the highest load compared to the other type 3 panels with thicknesses of 40 and $50 \mathrm{~mm}$. The largest deformation occurred on the type 3 panel with a thickness of $40 \mathrm{~mm}$. From the result and analysis of the panels with thickness variation, it performed that all panels with a thickness of $60 \mathrm{~mm}$ could withstand the highest lateral loads with smaller deformations. 
Annisa Fitria Agustina et al.

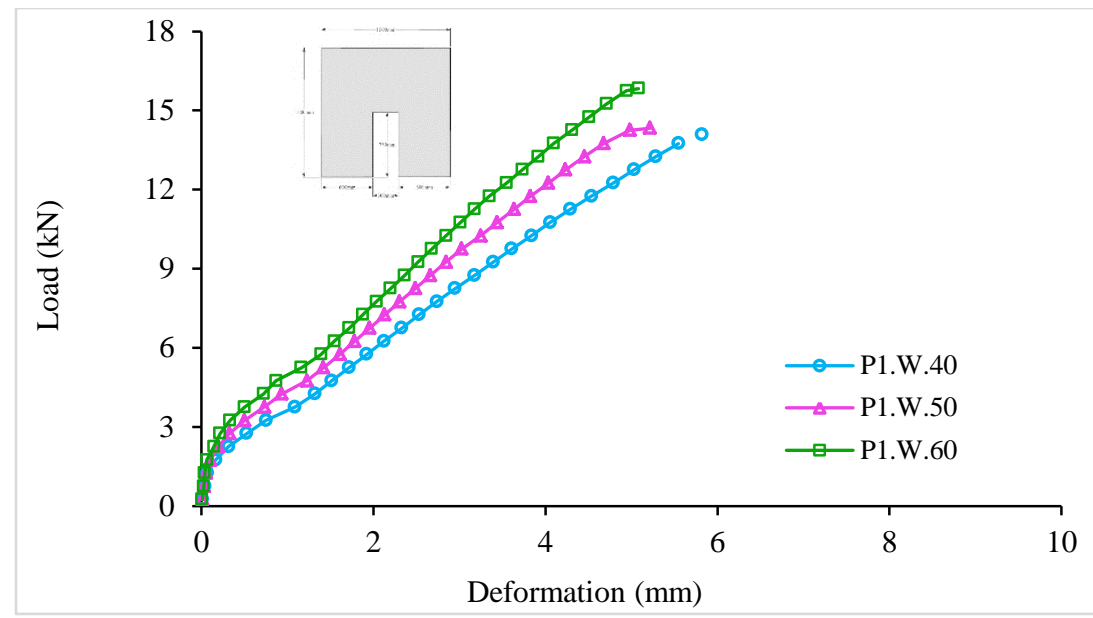

Figure 9 Load vs deformation curves of type 1 panel with thickness variation with wire mesh

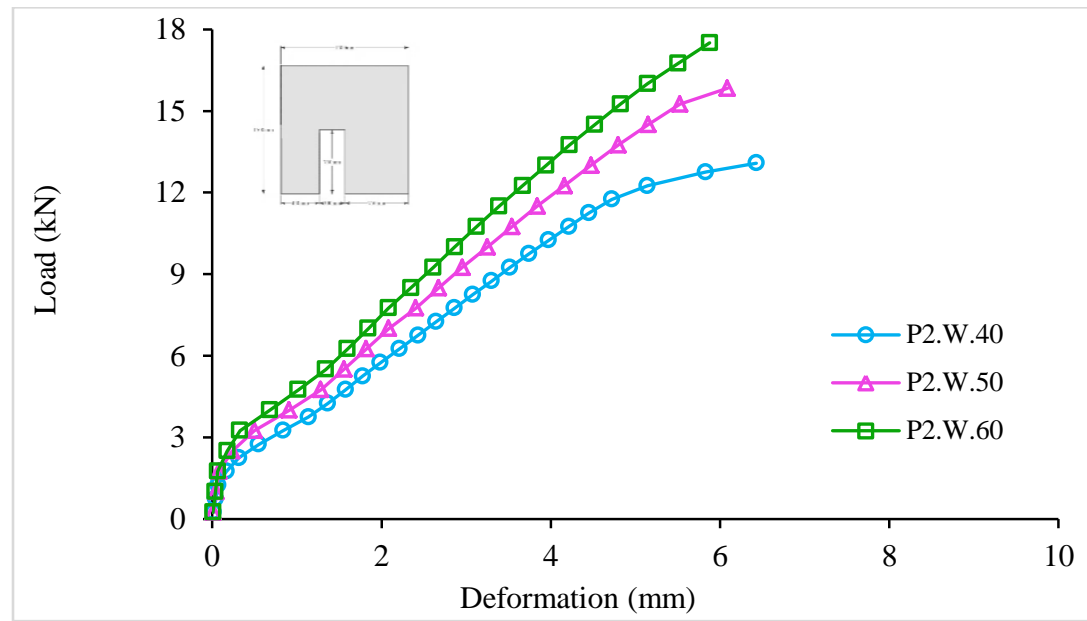

Figure 10 Load vs deformation curves of type 2 panel with thickness variation with wire mesh

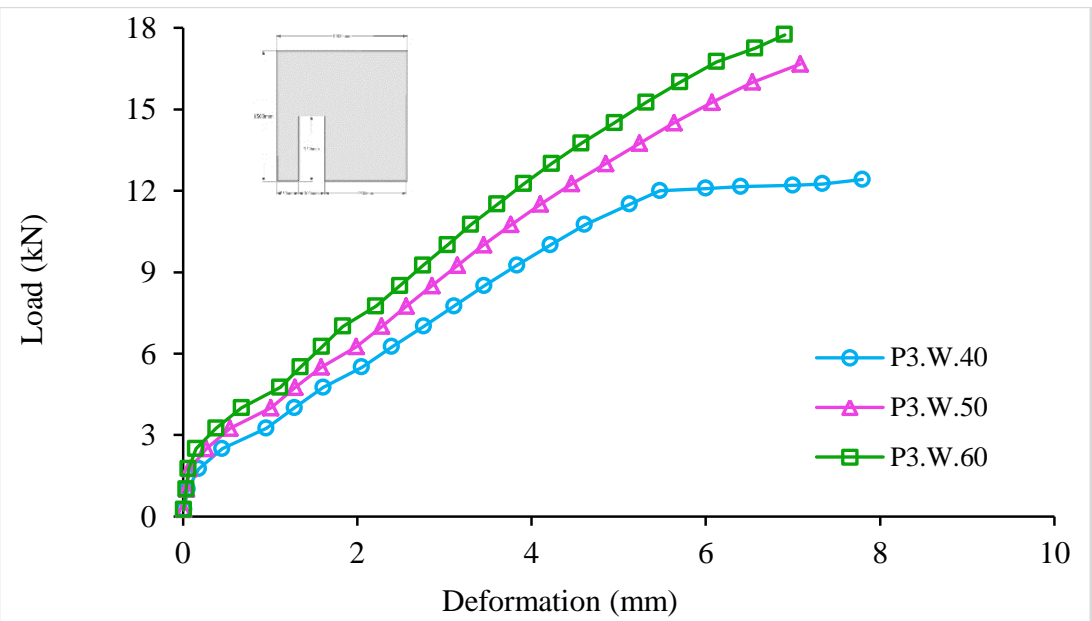

Figure 11 Load vs deformation curves of type 3 panel with thickness variation with wire mesh 
3.1.4Load and deformation connection in panel with wire mesh and variation in door opening position

Figures 12 to 14 present the relation between the load and deformation that occurred on the panels with wire mesh and variation of door opening positions. The compared panels had the same thickness, then it showed the panel that could resist the highest load. Figure 12 shows the load and deformation relation of the $40 \mathrm{~mm}$ thick panel with a variation of the door opening position. The type 1 panel collapsed on a static monotonic load of $14.08 \mathrm{kN}$ with deformation of $5.82 \mathrm{~mm}$. The type 2 panel collapsed at a load of $13.08 \mathrm{kN}$ with a $6.43 \mathrm{~mm}$ deformation. The type 3 panel collapsed at $12.42 \mathrm{kN}$ load with a $7.80 \mathrm{~mm}$ deformation. The type 1 panels with a thickness of 40 $\mathrm{mm}$ could resist the largest monotonic static load, while the largest deformation occurred on type 3 panels.

Load and deformation relation with a variation of door opening position on the panels with wire mesh and a thickness of $50 \mathrm{~mm}$ can be seen in Figure 13 . The type 1 panel collapsed at a load of $14.33 \mathrm{kN}$ with a $5.22 \mathrm{~mm}$ deformation. The type 2 panel collapsed at a load of $15.83 \mathrm{kN}$ with deformation of $6.09 \mathrm{~mm}$. The type 3 panel collapsed at a load of $16.67 \mathrm{kN}$ with a $7.09 \mathrm{~mm}$ deformation. It was showed that the type 3 panel with a thickness of $50 \mathrm{~mm}$ could withstand the highest static monotonic load and the largest deformation.

Figure 14 shows the load and deformation relation curves of panels with $60 \mathrm{~mm}$ thickness with wire mesh and a variation of the door opening position. The type 1 panel could resist static monotonic load up to $15.83 \mathrm{kN}$ with deformation of $5.08 \mathrm{~mm}$. The type 2 panel could withstand static monotonic loads up to $17.50 \mathrm{kN}$ with a $5.88 \mathrm{~mm}$ deformation. The type 3 panel collapsed under the static monotonic load of $18.00 \mathrm{kN}$ with a $6.90 \mathrm{~mm}$ deformation. This showed that the type 3 panel with a thickness of 60 $\mathrm{mm}$ could resist the highest static monotonic load and the largest deformation.

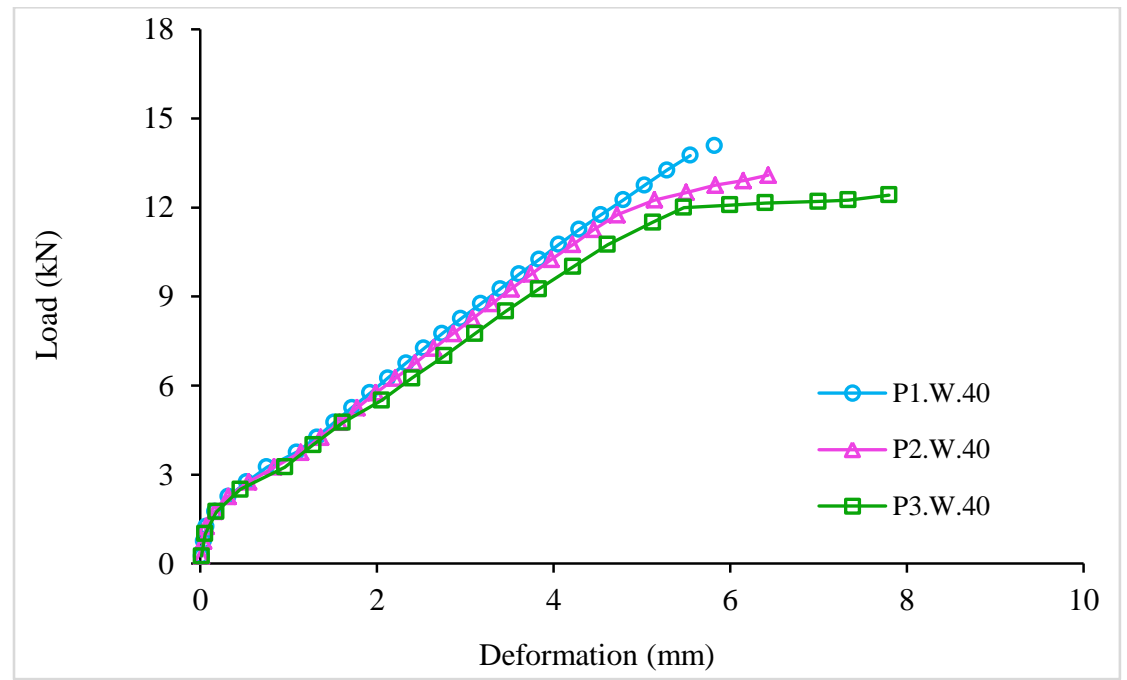

Figure 12 Load vs deformation curves with a variation of door opening position with a thickness of $40 \mathrm{~mm}$ and wire mesh 
Annisa Fitria Agustina et al.

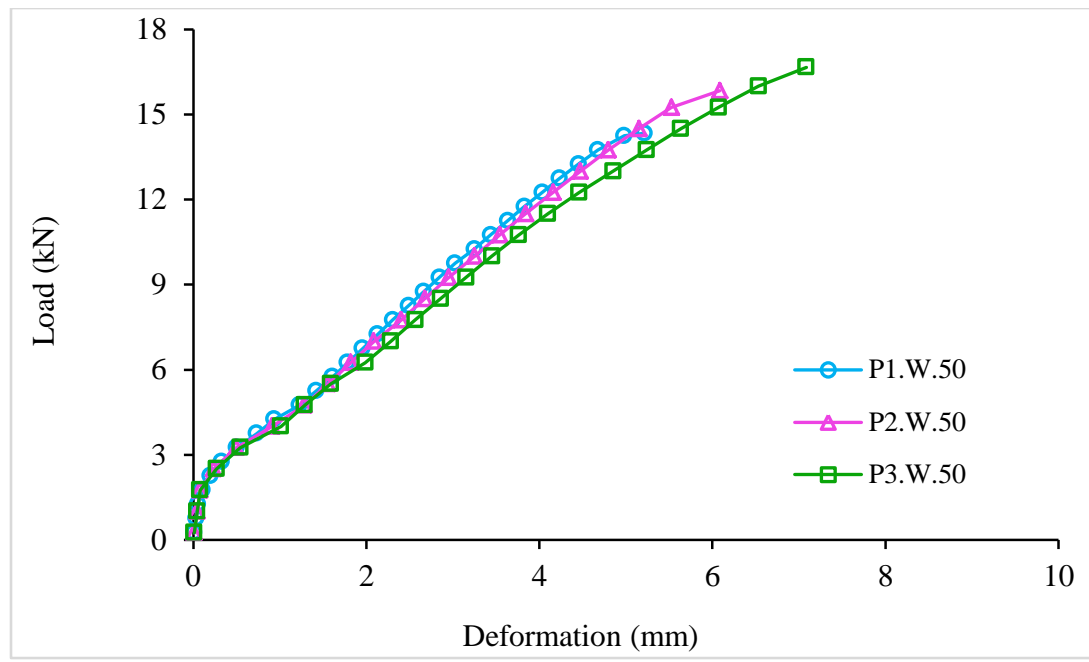

Figure 13 Load vs deformation curves with a variation of door opening position with a thickness of $50 \mathrm{~mm}$ and wire mesh

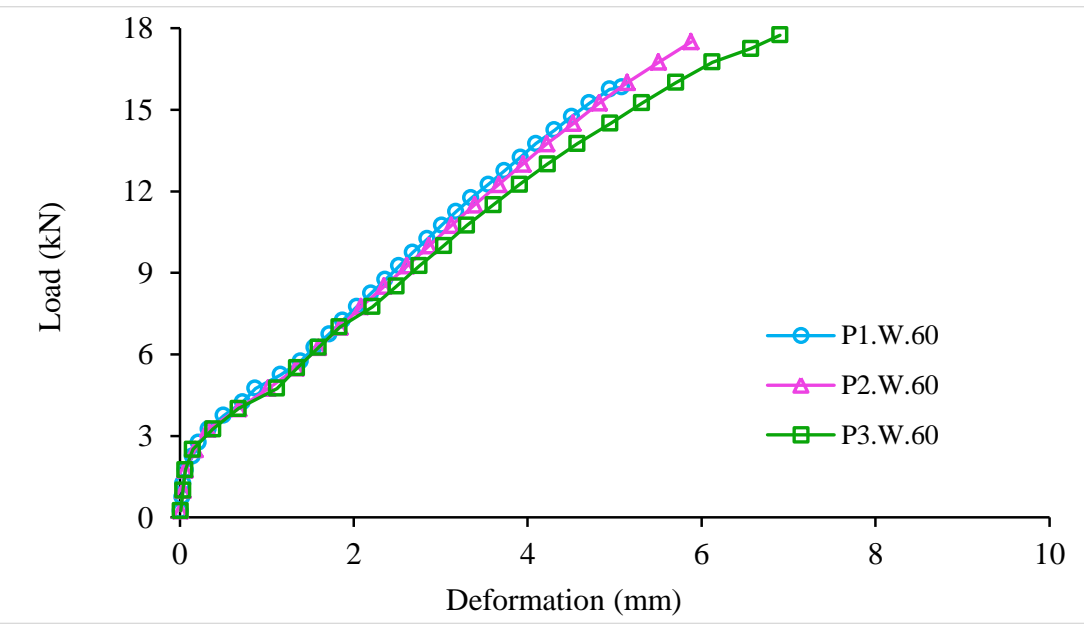

Figure 14 Load vs deformation curves with a variation of door opening position with a thickness of $60 \mathrm{~mm}$ and wire mesh

\subsection{Deformation shape}

3.2.1Deformation shape of type 1 panels without wire mesh

The deformation shapes were the results of an analysis using equations (1) and (2) which had been drawn in colored pictures. Figure 15 shows the shape of the deformation of type 1 panel with a thickness of $40 \mathrm{~mm}$ without wire mesh. The maximum deformation was $6.54 \mathrm{~mm}$ and indicated on the red color area with a range of 5.39 to $6.54 \mathrm{~mm}$. The dark blue area represented the tensile part that occurred on the panel with a deformation ranged from 3.83 to $2.68 \mathrm{~mm}$. This was due to the bending that occurred in the tensile area and changed the form of the panel [16].
Figure 16 represents the shape of the deformation of type 1 panel with a thickness of $50 \mathrm{~mm}$ without wire mesh. The maximum deformation was $21.56 \mathrm{~mm}$ in the red areas with a range of 18.07 to $21.56 \mathrm{~mm}$ and located above the panels. The deformation on the dark blue areas indicated a bending part of the side of the panel with a deformation ranged from 9.87 to $6.38 \mathrm{~mm}$.

The shape of deformation that occurred on a type 1 panel with a thickness of $60 \mathrm{~mm}$ without wire mesh is shown in Figure 17. The maximum deformation occurred in a red area above the panel with a deformation ranged from 15.24 to $18.13 \mathrm{~mm}$. The dark blue area represented the bending with a deformation ranged from 7.96 to $5.06 \mathrm{~mm}$ located on the left side of the panel. 


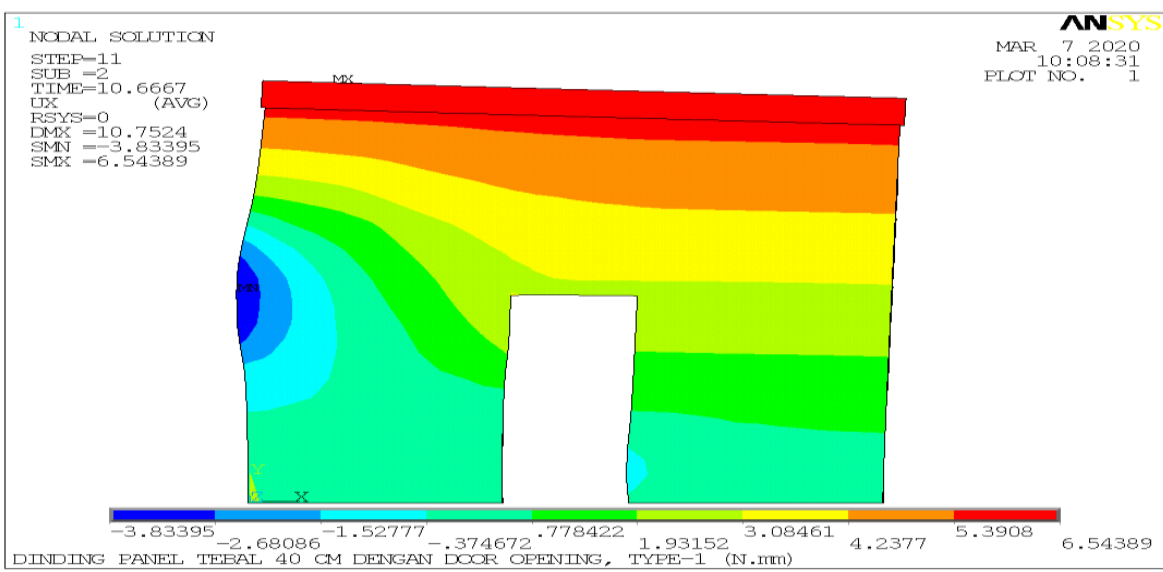

Figure 15 The shape of deformation of type 1 panel with a thickness of $40 \mathrm{~mm}$ and without wire mesh

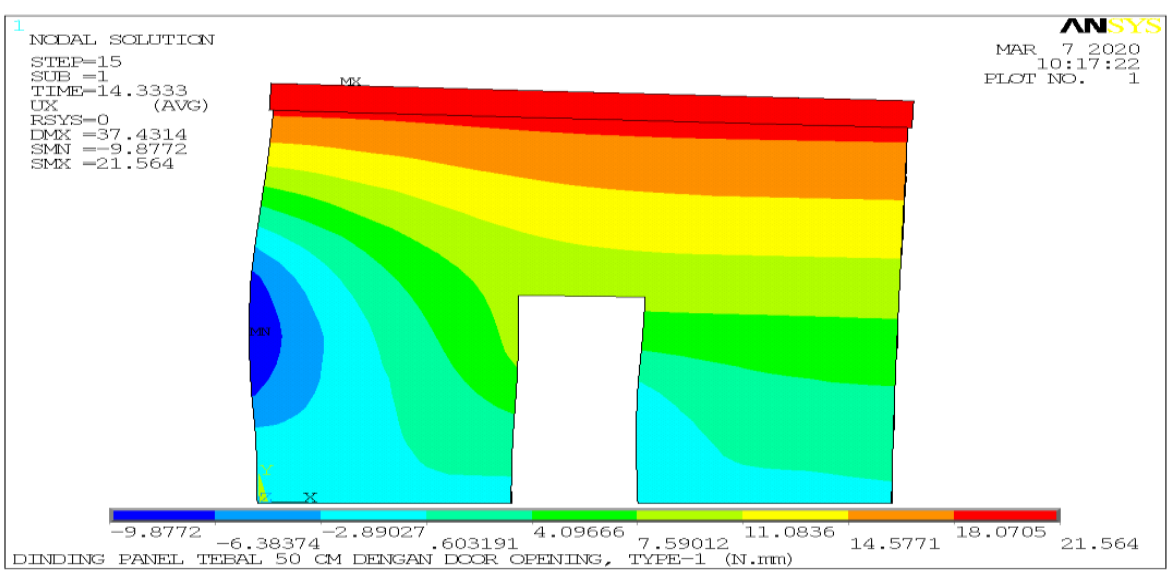

Figure 16 The deformation shape of type 1 panel with a thickness of $50 \mathrm{~mm}$ and without wire mesh

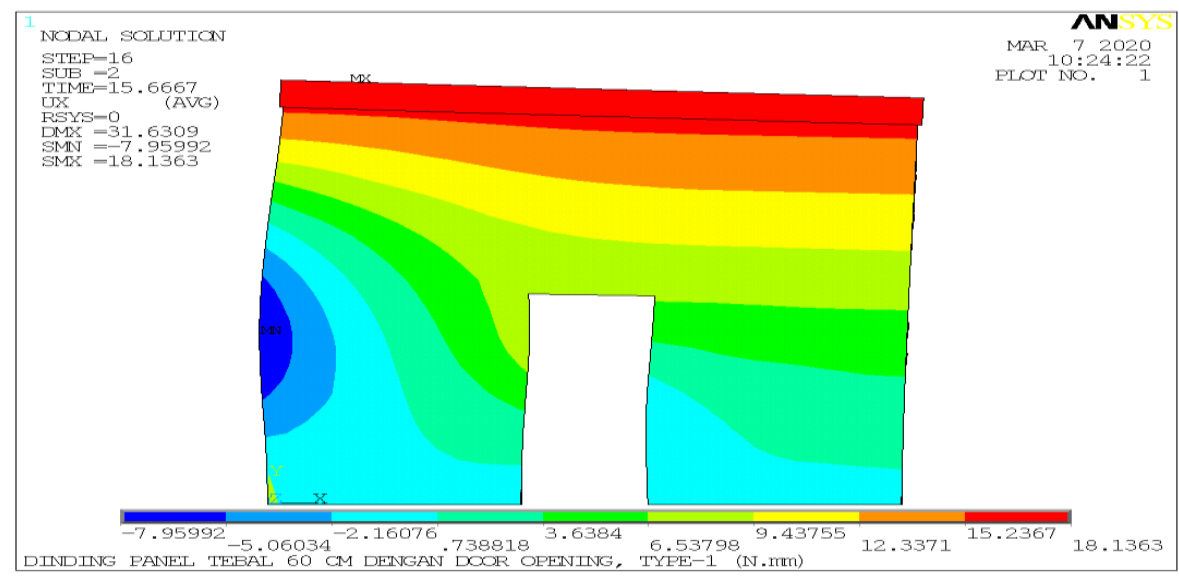

Figure 17 The deformation shape of type 1 panel with a thickness of $60 \mathrm{~mm}$ and without wire mesh

3.2.2Deformation shape of type 2 panels without wire mesh

The shape of deformation that occurred on the type 2 panel with a thickness of $40 \mathrm{~mm}$ without wire mesh is shown in Figure 18. The maximum deformation occurred in a red area located at the top of the panel with a deformation ranged from 18.62 to $22.16 \mathrm{~mm}$. The dark blue area shows a tensile panel part with a deformation ranged from 9.68 to $6.14 \mathrm{~mm}$ on the left side of the panel. 
Figure 19 shows the shape of deformation of the type 2 panel with a thickness of $50 \mathrm{~mm}$ without wire mesh. The maximum deformation that occurred on the type 2 panel was $28.09 \mathrm{~mm}$ at the top of the panel and shown in the red area with a range of 23.87 to $28.09 \mathrm{~mm}$. The darkest blue area on the left panel shows the tensile that occurred with a deformation ranged from 9.85 to $5.63 \mathrm{~mm}$.
Figure 20 shows the deformation shape of type 2 panel 2 with a thickness of $60 \mathrm{~mm}$ without wire mesh. The maximum deformation of $25.68 \mathrm{~mm}$ in a red area ranged from 21.77 to $25.68 \mathrm{~mm}$ and was located at the top of the panel. The deformation on a dark blue area indicated a pulled panel section with a deformation ranged from 9.51 to $5.60 \mathrm{~mm}$.

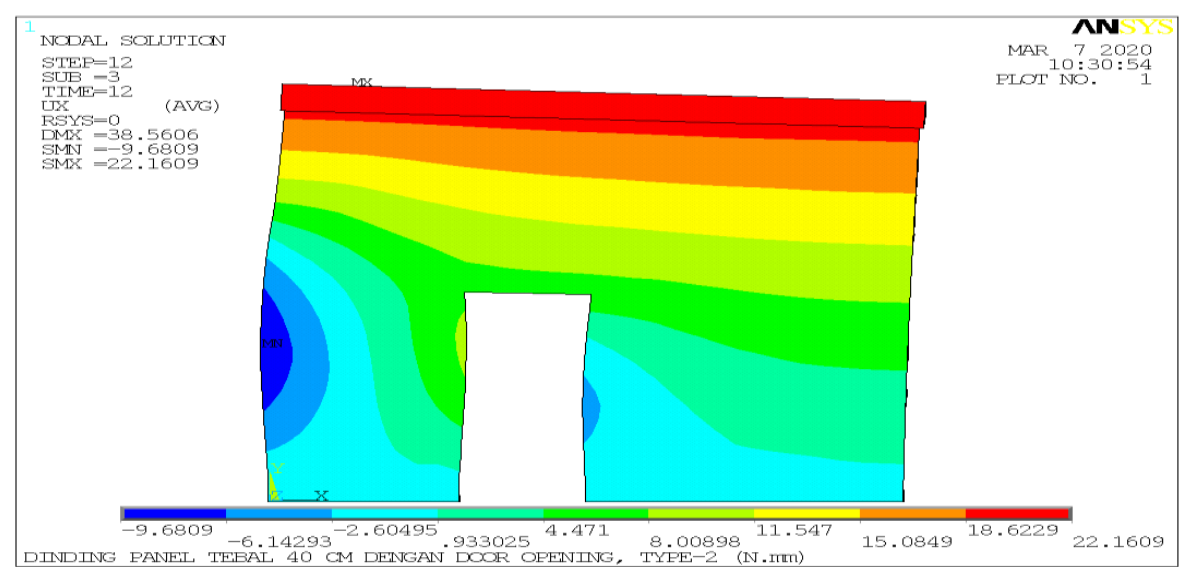

Figure 18 The deformation shape of type 2 panel with a thickness of $40 \mathrm{~mm}$ and without wire mesh

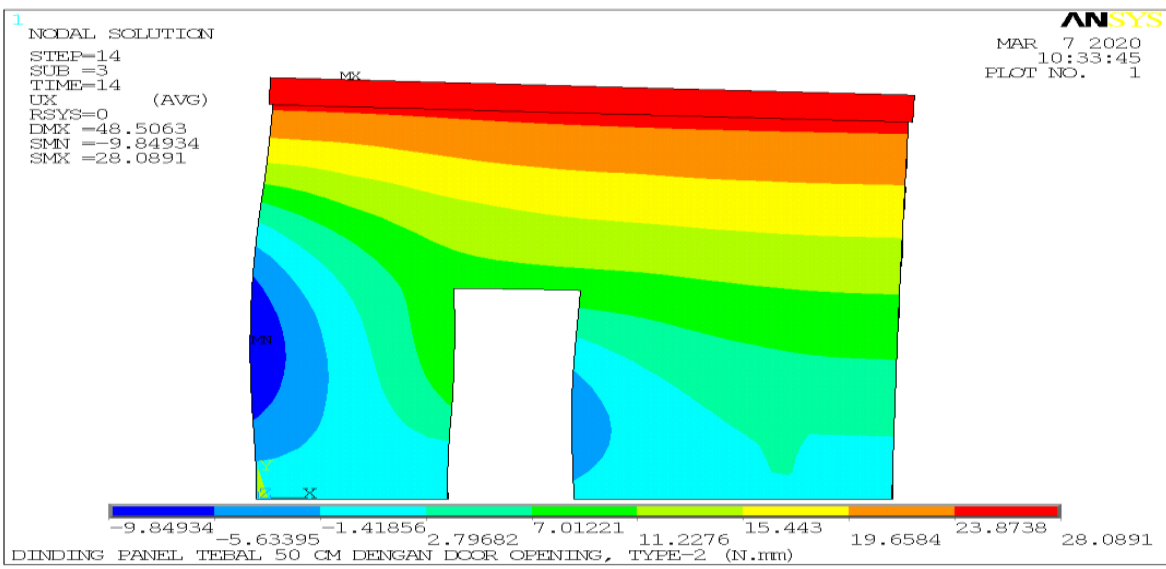

Figure 19 The deformation shape of type 2 panel with a thickness of $50 \mathrm{~mm}$ and without wire mesh 


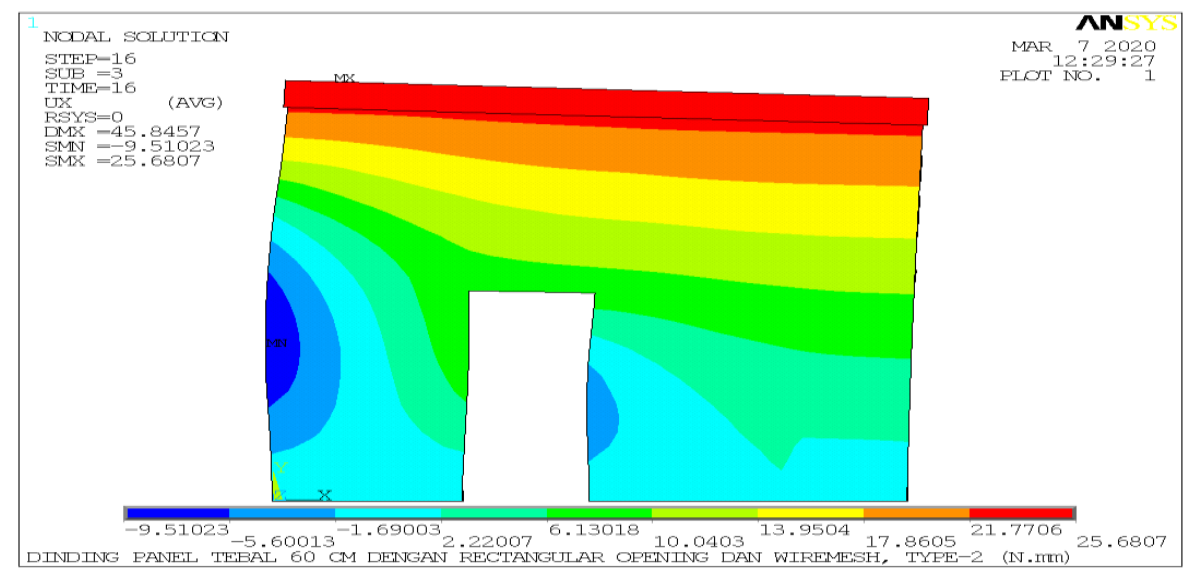

Figure 20 The deformation shape of type 2 panel with a thickness of $60 \mathrm{~mm}$ and without wire mesh

3.2.3 Deformation shape of type 3 Panels without wire mesh

Figures 21 to 23 show the shape of deformation that occurred on type 3 panels with thickness variation without wire mesh. Figure 21 shows the shape of deformation of type 3 panel with a thickness of 40 $\mathrm{mm}$ without wire mesh. The maximum deformation of $30.27 \mathrm{~mm}$ was located at the top of the panel, which was shown in the red area ranging from 25.55 to $30.27 \mathrm{~mm}$. The darkest blue area represented a tensile force that occurred on the panel with a deformation ranged from 12.24 to $7.52 \mathrm{~mm}$.

The shape of deformation that occurred on the type 3 panel with a thickness of $50 \mathrm{~mm}$ and without wire mesh is shown in Figure 22. The maximum deformation occurred in a red area located at the top of the panel with a deformation ranged from 22.74 to $26.93 \mathrm{~mm}$. The dark blue area on the left side of the panel showed a tensioned part with a deformation ranged from 10.75 to $6.57 \mathrm{~mm}$.

The deformation shape in Figure 23 represents the type 3 panel condition. This panel had a thickness of $60 \mathrm{~mm}$ and without wire mesh. A maximum deformation of $22.98 \mathrm{~mm}$ on a red area with a range of 19.33 to $22.98 \mathrm{~mm}$ was located at the top of the panel. The deformation on a darkest blue area indicated a pulled part with a deformation ranged from 9.93 to $6.27 \mathrm{~mm}$.

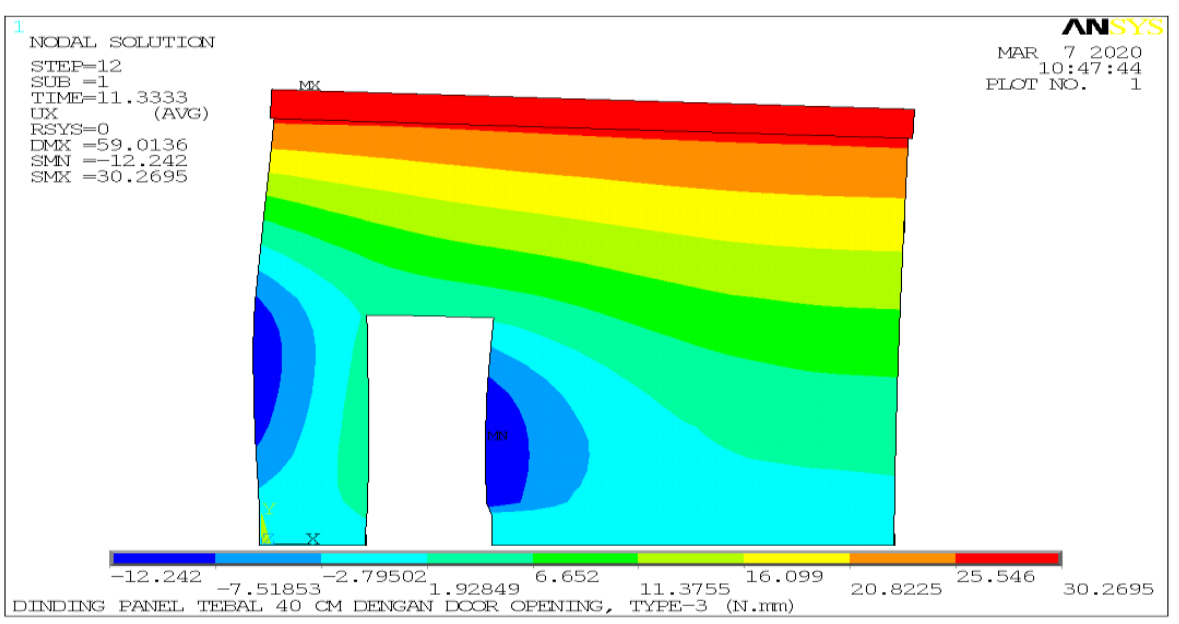

Figure 21 The deformation shape of type 3 panel with a thickness of $40 \mathrm{~mm}$ and without wire mesh 


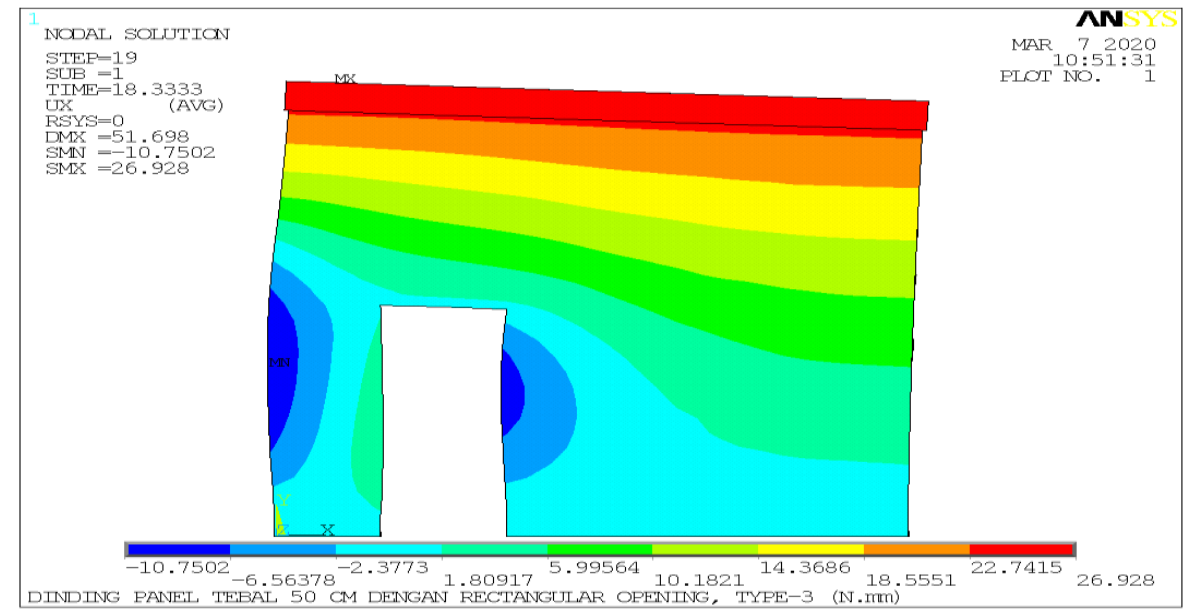

Figure 22 The deformation shape of type 3 panel with a thickness of $50 \mathrm{~mm}$ and without wire mesh

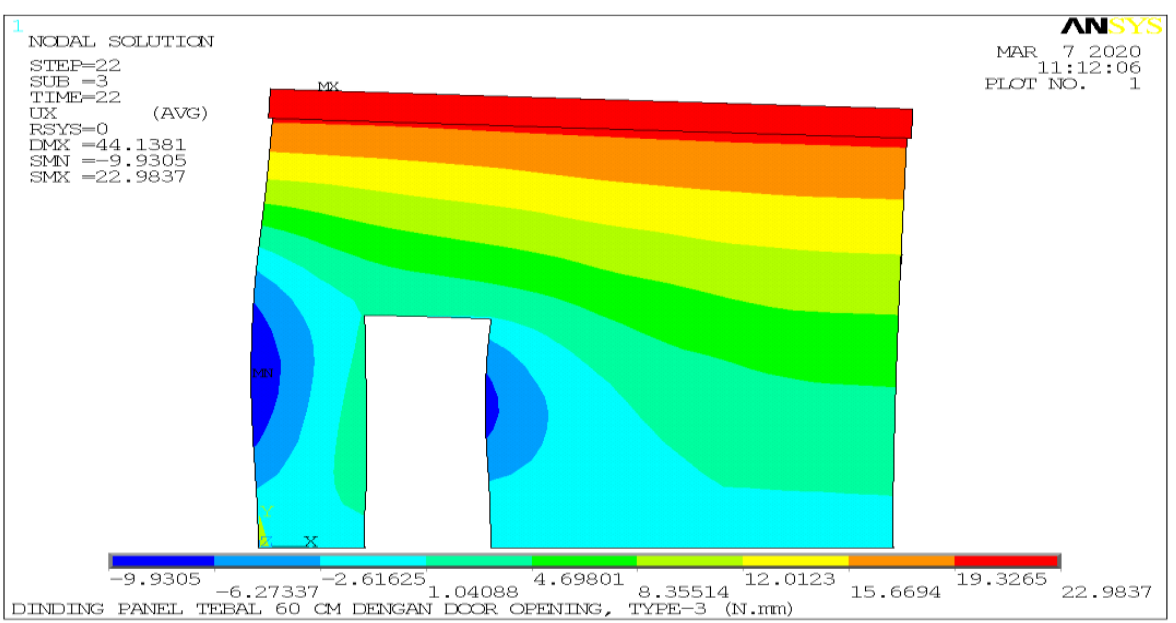

Figure 23 The deformation shape of type 3 panel with a thickness of $60 \mathrm{~mm}$ and without wire mesh

3.2.4 Deformation shape of type 1 panels with wire mesh

Figures 24 and 25 present the forms of deformation that occurred on the type 1 panels with wire mesh and thickness variations of $40 \mathrm{~mm}, 50 \mathrm{~mm}$, and 60 $\mathrm{mm}$. Figure 24 shows the shape of the deformation of type 1 panel with a wire mesh with a thickness of 40 $\mathrm{mm}$. The maximum deformation of $5.84 \mathrm{~mm}$ on a red area ranged from 5.19 to $5.84 \mathrm{~mm}$ and was located at the top of the panel. The deformation on a dark blue area indicated a tensile section with a deformation ranged from 0.00 to $0.65 \mathrm{~mm}$.

Figure 25 shows the deformation shape of a type 1 panel with a wire mesh with a thickness of $50 \mathrm{~mm}$. A maximum deformation of $5.22 \mathrm{~mm}$ was located at the top of the panel in a red area with a range of 4.63 $5.22 \mathrm{~mm}$. The leftmost dark blue panel shows the tensile that occurs on the panel with a $0.07-0.51 \mathrm{~mm}$ deformation range.

The deformation shape that occurs on a type 1 panel with wire mesh at a thickness of $60 \mathrm{~mm}$ can be seen in Figure 26. The maximum deformation occurred in a red area above the panel with a deformation range of $4.51-5.08 \mathrm{~mm}$. The dark blue area shows the location of a tensile force with a deformation range of $0.07-0.49 \mathrm{~mm}$ located on the left side of the panel. 


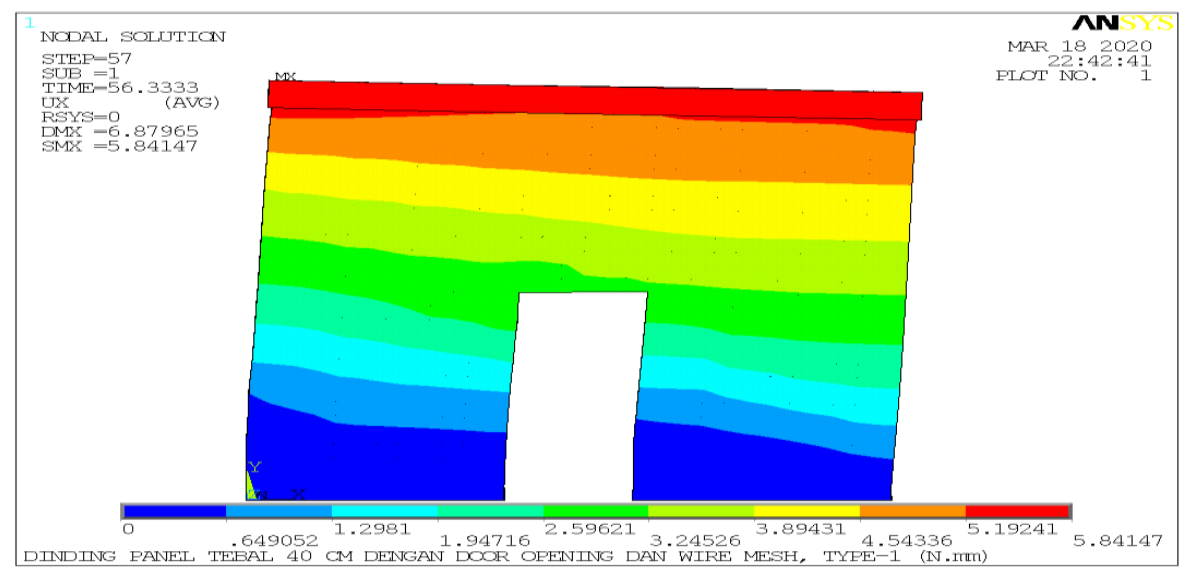

Figure 24 The deformation shape of type 1 panel with a thickness of $40 \mathrm{~mm}$ and wire mesh

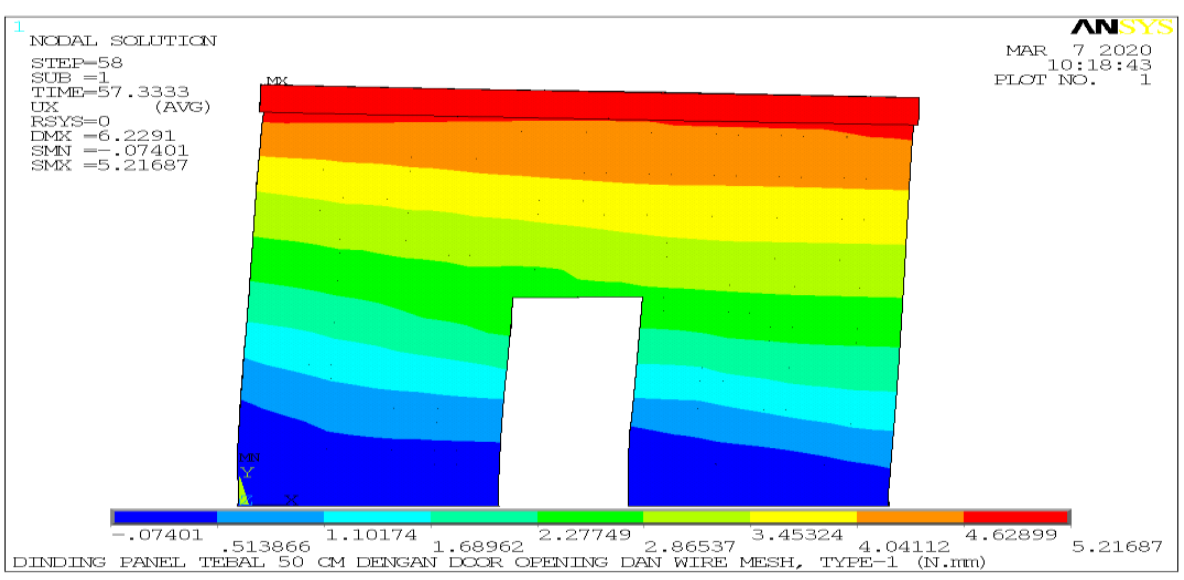

Figure 25 Deformation shape of type 1 panel with a thickness of $50 \mathrm{~mm}$ and wire mesh

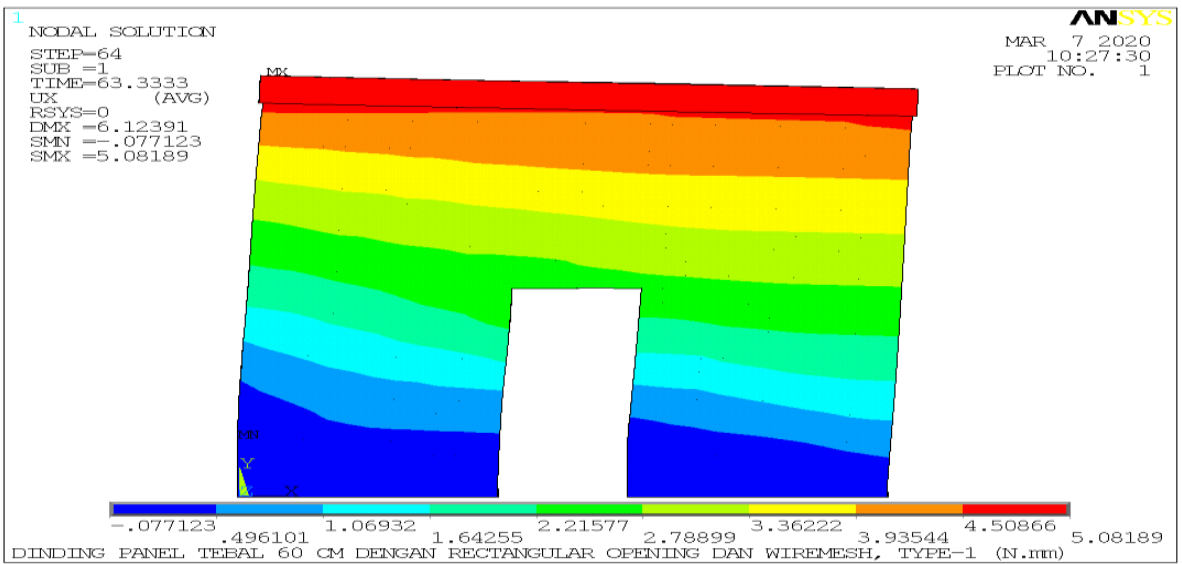

Figure 26 Deformation shape of type 1 panel with a thickness of $60 \mathrm{~mm}$ and wire mesh

3.2.5 Shape deformation of type 2 panels with wire mesh

Figure 27 shows the type 2 panels deformation with a thickness of $40 \mathrm{~mm}$ and wire mesh. The maximum deformation that occurred was $6.44 \mathrm{~mm}$ located at the top of the panel in the red area with a range of 5.72
$6.44 \mathrm{~mm}$. The darkest blue area shows the tensioned part with a deformation range of $0.00-0.71 \mathrm{~mm}$. The shape of deformation that occurs on the type 2 panel with a thickness of $50 \mathrm{~mm}$ and wire mesh can be seen in Figure 28. The maximum deformation occurred in a red area at the top of the panel with a deformation 
range of 5.41-6.09 $\mathrm{mm}$. The darkest blue area shows a tensioned part with a $0.00-0.67 \mathrm{~mm}$ deformation range located on the left side of the panel.

Figure 29 presents a shape of deformation that occurs on the type 2 panel with a thickness of $60 \mathrm{~mm}$ and wire mesh. The maximum deformation of $7.08 \mathrm{~mm}$ occurred in the red area with a range of 6.28-7.08 $\mathrm{mm}$ located at the top of the panel. The deformation on a dark blue area indicated a tensioned part with a deformation range of $0.04-0.74 \mathrm{~mm}$.

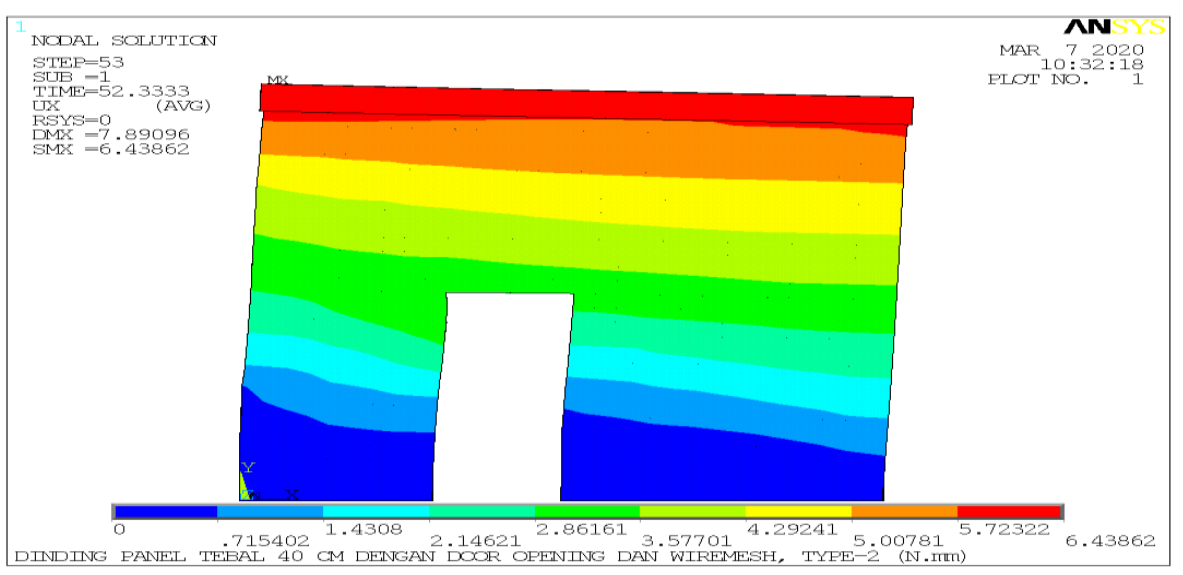

Figure 27 Deformation shape of the type 2 panel with a thickness of $40 \mathrm{~mm}$ and wire mesh

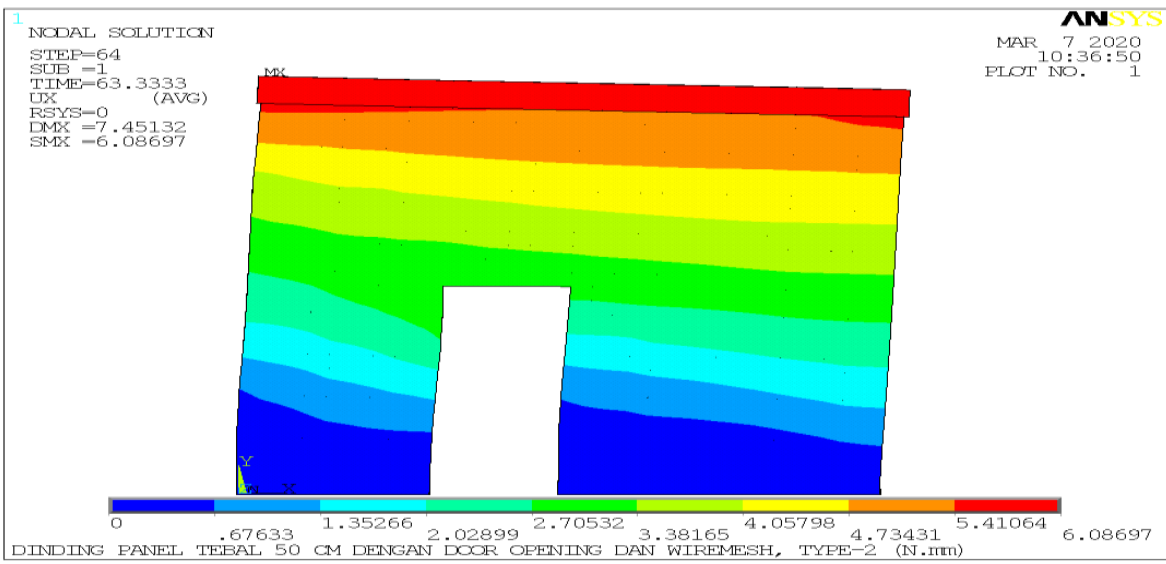

Figure 28 Deformation shape of the type 2 panel with a thickness of $50 \mathrm{~mm}$ and wire mesh

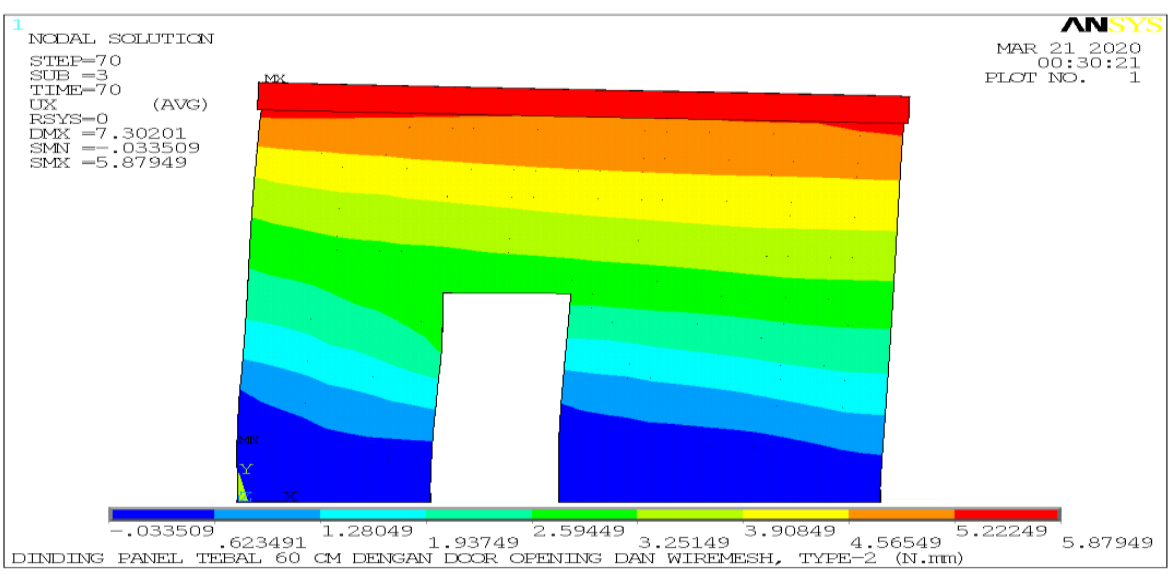

Figure 29 Deformation shape of the type 2 panel with a thickness of $60 \mathrm{~mm}$ and wire mesh 
3.2.6 Shape deformation of type $\mathbf{3}$ panel with wire mesh The deformation shape that occurred on the type 3 panel with a wire mesh and a thickness of $40 \mathrm{~mm}$ is shown in Figure 30. The maximum deformation occurred in a red area located above the panel with a deformation range of $6.84-7.81 \mathrm{~mm}$. The dark blue shows a tensioned part with a deformation range of $0.08-0.88 \mathrm{~mm}$.

Figure 31 shows the deformation form of the type 3 panel with a thickness of $50 \mathrm{~mm}$ and wire mesh. The maximum deformation that occurred was $7.09 \mathrm{~mm}$ located at the top of the panel, which was indicated on the red color area with a range of $6.29-7.09 \mathrm{~mm}$. The darkest blue panel shows the tensioned area with a deformation range of 0.15 to $0.65 \mathrm{~mm}$. Figure 32 shows the deformation shape of the type 3 panel 3 with a thickness of $60 \mathrm{~mm}$ and wire mesh. A maximum deformation of $7.44 \mathrm{~mm}$ on a red area with a range of $6.58-7.44 \mathrm{~mm}$ was located above the panel. The deformation on a dark blue area indicated a tensioned section with a deformation range of 0.27 to $0.58 \mathrm{~mm}$.

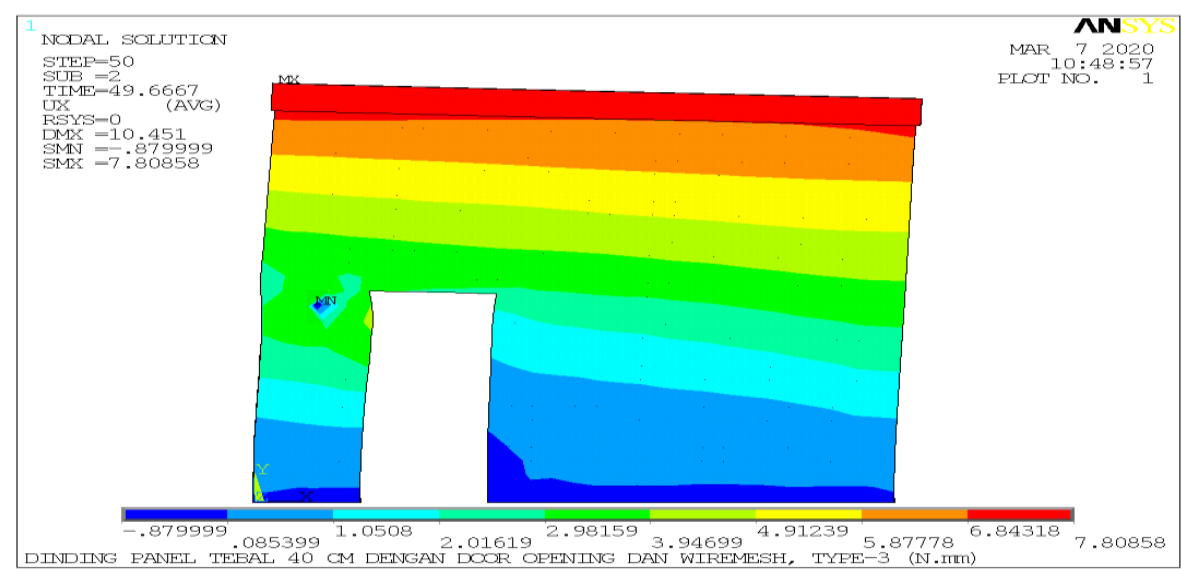

Figure 30 Deformation shape of the type 3 panel with a thickness of $40 \mathrm{~mm}$ and wire mesh

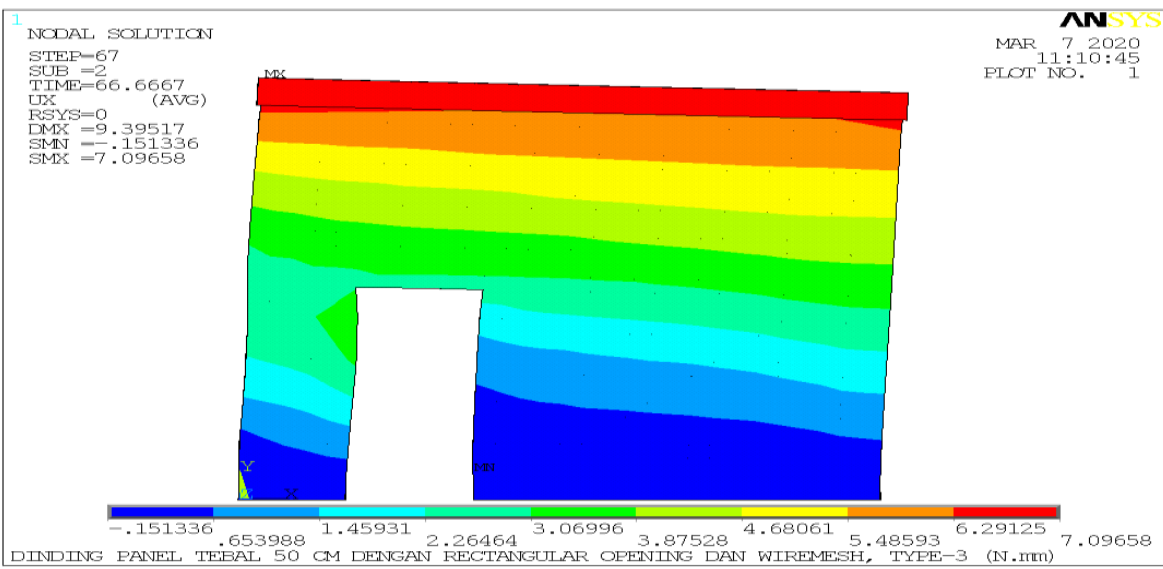

Figure 31 The deformation shape of the type 3 panel with a thickness of $50 \mathrm{~mm}$ and wire mesh 


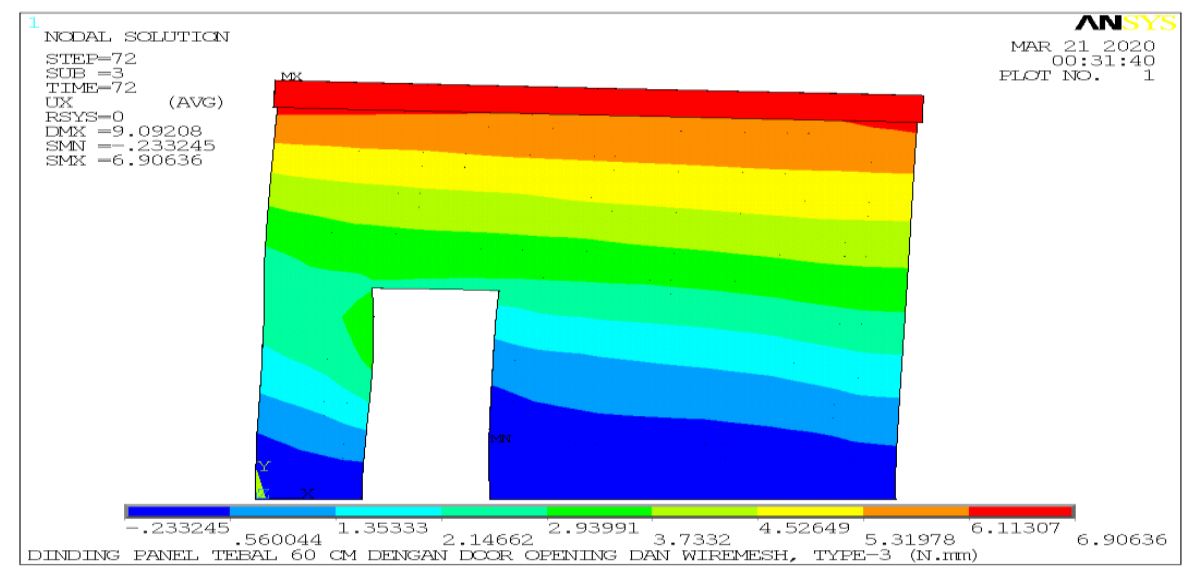

Figure 32 The deformation shape of the type 3 panel with a thickness of $60 \mathrm{~mm}$ and wire mesh

\section{Conclusion and future work}

The variation in the door opening position influenced the occurred deformation values. The position of the door opening on type 3 panels caused the greatest deformation compared to type 1 and 2 panels. The more centric the door opening position to the panels then the smaller deformations. The panel thickness affected the durability of the panel in resisting lateral loads. The thicker the panels, the higher loads could be resisted by the panels. The use of wire mesh provided more rigid panels, then panels could resist higher loads. On the opposite, the use of wire mesh caused smaller deformations.

There are some needed further observations on the behavior of lightweight concrete under tension condition as well as the optimum thickness of the panel. The analysis results of the nonlinear modelings would be verified using experimental works.

\section{Acknowledgment}

The research presented in this paper was supported by a grant from Sriwijaya University with a contract number 0179.014/UN9/SB3.LPPM.PT/2020.

\section{Conflicts of interest}

The authors have no conflicts of interest to declare.

\section{References}

[1] Prabha P, Palani GS, Lakshmanan N, Senthil R. Behaviour of steel-foam concrete composite panel under in-plane lateral load. Journal of Constructional Steel Research. 2017; 139:437-48.

[2] Sousa L, Monteiro R. Seismic retrofit options for nonstructural building partition walls: Impact on loss estimation and cost-benefit analysis. Engineering Structures. 2018; 161:8-27.

[3] Ridha MM, Li D, Clifton GC, Ma X. Structural behavior of composite panels made of lightly profiled steel skins and lightweight concrete under concentric and eccentric loads. Journal of Structural Engineering. 2019; 145(10):04019093.

[4] Assaad J, Chakar E, Zéhil GP. Testing and modeling the behavior of sandwich lightweight panels against wind and seismic loads. Engineering Structures. 2018; 175:457-66.

[5] Fragomeni S, Doh JH, Lee DJ. Behavior of axially loaded concrete wall panels with openings: an experimental study. Advances in Structural Engineering. 2012; 15(8):1345-58.

[6] Irawan T, Idris Y. Mechanical properties of foamed concrete with additional pineapple fiber and polypropylene fiber. In Journal of Physics: Conference Series 2019. IOP Publishing.

[7] Saloma, Hanafiah, Urmila D. The effect of water binder ratio and fly ash on the properties of foamed concrete. In AIP conference proceedings 2017. AIP Publishing LLC.

[8] Nurjannah SA, Budiono B, Imran I, Sugiri S. The hysteretic behavior of partially pre-stressed beamcolumn joint sub-assemblages made of reactive powder concrete. Journal of Engineering and Technological Sciences. 2016; 48(5):550-70.

[9] Wang J, Hu B, Soon JH. Physical and mechanical properties of a bulk lightweight concrete with expanded polystyrene (EPS) beads and soft marine clay. Materials. 2019; 12(10):1662.

[10] Nurjannah SA, Budiono B, Imran B. Influence of partial prestressing ratio on hysteretic behavior of beam-column subassemblage using reactive powder concrete materials, International Journal of Scientific \& Technology Research. 2020; 9(2):1933-41.

[11] Gherbi A, Dahmani L, Boudjemia A. Study on two way reinforced concrete slab using ANSYS with different boundary conditions and loading. International Journal of Civil and Environmental Engineering. 2018; 12(12):1151-6.

[12] Alchaar A, Abed F. Finite element analysis of a thinshell concrete sandwich panel under eccentric loading. Journal of Building Engineering. 2020; 32:101804. 
[13] https://www.astm.org/Standards/E72.htm. Accessed 25 September 2020.

[14] Bacciocchi M, Tarantino AM. Critical buckling load of honeycomb sandwich panels reinforced by threephase orthotropic skins enhanced by carbon nanotubes. Composite Structures. 2020; 237:111904.

[15] Ocampo-Escobar AF, Vidot-Vega AL. Effects of concrete parameters in the lateral stiffness of reinforced concrete squat walls. International Journal of Advanced Structural Engineering. 2019; 11(3):32130.

[16] Abdul-Razzaq KS, Mohammeda AH, Mohammedalia TK. Finite element modeling of post-tensioned twoway concrete slabs under flexural loading. Civil Engineering Journal. 2018; 4(1):1-10.

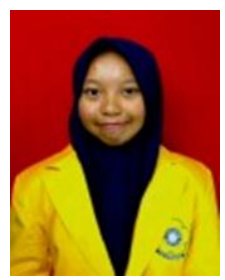

Annisa Fitria Agustina is a student in the Civil Engineering Department, Faculty of Engineering, Sriwijaya University, Indonesia. Her research interest is Lightweight Concrete for Earthquake-Resistant Construction.

Email: salomaunsri@gmail.com

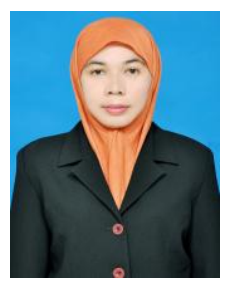

Saloma is a lecturer in the Civil Engineering Department, Faculty of Engineering, Sriwijaya University, Indonesia. She received a Doktor in Civil Engineering from Institut Teknologi Bandung in 2014. She is Head of Graduate of Civil Engineering at Sriwijaya University. Her research focuses on Geopolymer Concrete, Nanomaterial Concrete, Lightweight Concrete, Reactive Powder Concrete, Self Compacting Concrete, Cold-Formed Steel, and LightWeight Construction.

Email: salomaunsri@gmail.com

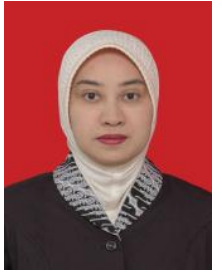

Siti Aisyah Nurjannah is a lecturer in the Civil Engineering Department, Faculty of Engineering, Sriwijaya University, Indonesia. She received a Doktor in Civil Engineering from Institut Teknologi Bandung in 2016. Her research focuses on Reactive Powder Concrete, Light-weight Concrete, Earthquake Resistance Structures, and Nonlinear Structural Modeling.

Email: sanurjannah@gmail.com

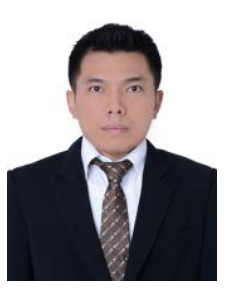

Arie Putra Usman is a lecturer in the Civil Engineering Department, Faculty of Engineering, Sriwijaya University, Indonesia. She received a Doktor in Civil Engineering from Institut Teknologi Bandung in 2017. His research focuses on Wood Structures and Light-weight Concrete.

Email: arie.putrausman@gmail.com

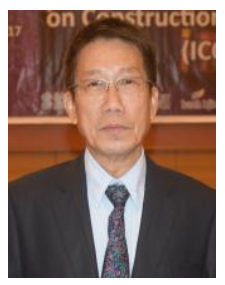

Hanafiah is a lecturer in the Civil Engineering Department, Faculty of Engineering, Sriwijaya University, Indonesia. He received a Doktor in Civil Engineering from Institut Teknologi Bandung in 1996. His research focuses on steel structures, Self-Compacting

Concrete,

Geopolymer Concrete, and Light-Weight Concrete.

Email: hanafiah_dr@yahoo.com.sg 